\title{
Folic Acid Promotes Recycling of Tetrahydrobiopterin and Protects Against Hypoxia-Induced Pulmonary Hypertension by Recoupling Endothelial Nitric Oxide Synthase
}

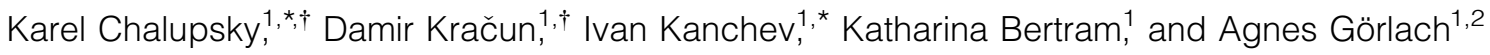

\begin{abstract}
Aims: Nitric oxide (NO) derived from endothelial NO synthase (eNOS) has been implicated in the adaptive response to hypoxia. An imbalance between 5,6,7,8-tetrahydrobiopterin $\left(\mathrm{BH}_{4}\right)$ and 7,8-dihydrobiopterin $\left(\mathrm{BH}_{2}\right)$ can result in eNOS uncoupling and the generation of superoxide instead of NO. Dihydrofolate reductase (DHFR) can recycle $\mathrm{BH}_{2}$ to $\mathrm{BH}_{4}$, leading to eNOS recoupling. However, the role of DHFR and eNOS recoupling in the response to hypoxia is not well understood. We hypothesized that increasing the capacity to recycle $\mathrm{BH}_{4}$ from $\mathrm{BH}_{2}$ would improve $\mathrm{NO}$ bioavailability as well as pulmonary vascular remodeling (PVR) and right ventricular hypertrophy $(\mathrm{RVH})$ as indicators of pulmonary hypertension $(\mathrm{PH})$ under hypoxic conditions. Results: In human pulmonary artery endothelial cells and murine pulmonary arteries exposed to hypoxia, eNOS was uncoupled as indicated by reduced superoxide production in the presence of the nitric oxide synthase inhibitor, L-(G)-nitro-L-arginine methyl ester (L-NAME). Concomitantly, $\mathrm{NO}$ levels, $\mathrm{BH}_{4}$ availability, and expression of DHFR were diminished under hypoxia. Application of folic acid (FA) restored DHFR levels, NO bioavailability, and $\mathrm{BH}_{4}$ levels under hypoxia. Importantly, FA prevented the development of hypoxia-induced PVR, right ventricular pressure increase, and RVH. Innovation: FA-induced upregulation of DHFR recouples eNOS under hypoxia by improving $\mathrm{BH}_{4}$ recycling, thus preventing hypoxia-induced PH. Conclusion: FA might serve as a novel therapeutic option combating PH. Antioxid. Redox Signal. 23, 1076-1091.
\end{abstract}

\section{Introduction}

A DEQUATE SUPPLY of molecular oxygen is essential for the function of all organs in the body. In the pulmonary system, hypoxia can lead to structural changes of small pulmonary vessels (pulmonary vascular remodeling [PVR]) and the development of right ventricular hypertrophy (RVH) as hallmarks of pulmonary hypertension (PH).

Nitric oxide (NO) plays an important role in regulating $\mathrm{O}_{2}$ delivery through paracrine control of local vasomotor tone and central cardiovascular and respiratory responses (31). NO derived from the pulmonary endothelium has been con-

\section{Innovation}

In this study, we show for the first time that folic acid (FA) prevents uncoupling of endothelial nitric oxide synthase under hypoxia by promoting recycling of 5,6,7,8tetrahydrobiopterin due to restoration of dihydrofolate reductase expression. We further show for the first time that FA treatment protects against hypoxia-induced pulmonary vascular remodeling, right ventricular pressure increase, and right ventricular hypertrophy.

\footnotetext{
${ }^{1}$ Experimental and Molecular Pediatric Cardiology, German Heart Center Munich at the Technical University Munich, Munich, Germany.

${ }^{2}$ DZHK (German Centre for Cardiovascular Research), Partner Site Munich Heart Alliance, Munich, Germany.

*Current affiliation: Laboratory of Transgenic Models of Diseases, Institute of Molecular Genetics of the ASCR, v. v. i., Prague, Czech Republic.

${ }^{\dagger}$ These authors contributed equally to this work.
} 
sidered to be essential for maintaining pulmonary vascular homeostasis $(10,26)$.

In the pulmonary endothelium, $\mathrm{NO}$ is generated predominantly by the endothelial NO synthase (eNOS), which binds a number of cofactors to convert L-arginine and $\mathrm{O}_{2}$ to $\mathrm{L}$ citrulline and NO (56). eNOS is a homodimer comprising an $\mathrm{N}$-terminal (oxygenase) and a C-terminal (reductase) domain (68). For completion of the eNOS catalytic cycle, two electrons derived from the cellular NADPH pool and 5, 6, 7, 8tetrahydrobiopterin $\left(\mathrm{BH}_{4}\right)$ are needed per one produced $\mathrm{NO}$ molecule (53).

Evidence that NO derived from eNOS plays an important role in the pulmonary response to hypoxia came from genetically modified animal models. eNOS knockout mice have been described to be particularly sensitive to hypoxia and to develop $\mathrm{PH}$ in response to hypoxia more readily than wild-type mice $(19,60)$. On the contrary, overproduction of eNOS-derived NO in endothelial cells decreased remodeling of the pulmonary vasculature and RVH induced by chronic hypoxia (51).

Although the $\mathrm{K}_{\mathrm{m}}$ of eNOS for $\mathrm{O}_{2}$ has been reported to be in the range between 5 and $20 \mu M(54,55)$, thus allowing the enzyme to be functional even under hypoxic conditions, there are conflicting data regarding the regulation of $\mathrm{NO}$ and $\mathrm{eNOS}$ under low oxygen conditions. In the pulmonary circulation, hypoxia has been reported to increase, decrease, or not affect levels of $\mathrm{NO}$ or of its oxidation product, nitrite $(9,32,37,38$, $47,50,61,70)$, as well as of eNOS $(2,22,37-39,47,50,63$, 64,70 ), although modulation of eNOS activity or NO bioavailability did not always match with a corresponding change in eNOS expression. In fact, in addition to the supply with oxygen and substrates, eNOS activity is regulated by phosphorylation and various other post-translational mechanisms, as well as by interaction with modulatory proteins such as HSP90 or caveolin (26).

A critical role in modulating $\mathrm{NO}$ availability has been related to the cofactor, $\mathrm{BH}_{4}$. When $\mathrm{BH}_{4}$ levels are low, electrons are diverted to molecular oxygen rather than to $\mathrm{L}$-arginine, thus transforming eNOS into a pro-oxidant superoxide anion-generating enzyme- the so-called uncoupled eNOS $(62,66)$. This transformation of eNOS has been observed in several in vitro models, in animal models of cardiovascular diseases, and in patients with cardiovascular risk factors (26).

However, whether this transformation plays a role in the response of the pulmonary vascular endothelium toward hypoxia is not well understood. Findings that mice with disrupted $\mathrm{BH}_{4}$ synthesis developed $\mathrm{PH}$ in particular under hypoxia point toward an involvement of eNOS uncoupling in these conditions $(34,48)$.

In addition to $\mathrm{BH}_{4}$ deficiency, increased levels of the $\mathrm{BH}_{4}$ oxidation product, 7,8-dihydrobiopterin $\left(\mathrm{BH}_{2}\right)$, can result in eNOS uncoupling. $\mathrm{BH}_{2}$ is inactive for cofactor function, but binds eNOS with similar affinity as $\mathrm{BH}_{4}$ and thus can efficiently replace eNOS-bound $\mathrm{BH}_{4}(6,12)$. Thus, the ratio between $\mathrm{BH}_{4}$ and $\mathrm{BH}_{2}$, rather than absolute concentrations of $\mathrm{BH}_{4}$, might be detrimental for the shift from eNOS competent to the uncoupled state $(5,11)$. Net $\mathrm{BH}_{4}$ cellular bioavailability in the endothelium is derived from de novo $\mathrm{BH}_{4}$ synthesis by GTP cyclohydrolase I (GTPCH-1), loss of $\mathrm{BH}_{4}$ by oxidation to $\mathrm{BH}_{2}$, and regeneration of $\mathrm{BH}_{4}$ from $\mathrm{BH}_{2}$ by dihydrofolate reductase (DHFR) (49). $\mathrm{BH}_{2}$ to $\mathrm{BH}_{4}$ recycling might be preferable to $\mathrm{BH}_{4}$ de novo synthesis when it comes to fast adaptation to microenvironmental challenges such as low oxygen availability, although its importance for endothelial adaptation to hypoxia is not well understood.

We thus hypothesized that hypoxia might affect $\mathrm{BH}_{4}$ regeneration capacity, resulting in altered eNOS coupling and function. Folic acid (FA), widely used as a food supplement, is known to induce DHFR levels and to enhance DHFR activity, thereby stimulating the regeneration of $\mathrm{BH}_{4}$ from the inactive oxidized $\mathrm{BH}_{2}$ (25). In addition, FA has been recently reported to affect phosphorylation of eNOS (65) and to increase the effectiveness of $\mathrm{BH}_{4}$ on eNOS uncoupling (46), indicating multiple actions of this substance on NO metabolism. We therefore investigated the impact of FA on pulmonary endothelial NO and superoxide metabolism under hypoxia in vitro and on the response to chronic hypoxia in vivo. Our study suggests that FA supplementation might be a novel therapeutic strategy to improve NO bioavailability and to ameliorate symptoms of $\mathrm{PH}$ when oxygen supply is limited.

\section{Results}

\section{$\mathrm{NO}$ and $\mathrm{BH}_{4}$ bioavailability are decreased under hypoxia}

To characterize NO metabolism in human pulmonary artery endothelial cells (HPAECs) and isolated murine pulmonary arteries (PAs) under hypoxic conditions, cells or arteries were exposed for $24 \mathrm{~h}$ to hypoxia, and $\mathrm{NO}$ levels were determined by electron paramagnetic resonance (EPR) using iron $\left(2^{+}\right)$-diethyldithiocarbamic acid $\left[\mathrm{Fe}\left(2^{+}\right)(\right.$DETC) $]$colloid. In hypoxic HPAECs and PAs, NO production was decreased compared with normoxic controls (Fig. 1A). We further analyzed the levels of nitrite, a decomposition product of NO, in the supernatants of normoxic and hypoxic HPAECs and PAs by high-pressure liquid chromatography (HPLC). Similar to the situation with NO, nitrite release was decreased in hypoxic samples (Fig. 1B).

NO formation by nitric oxide synthases (NOS) requires adequate levels of $\mathrm{BH}_{4}$. We therefore determined the levels of $\mathrm{BH}_{4}$ as well as of its oxidation product, $\mathrm{BH}_{2}$. While $\mathrm{BH}_{4}$ levels were reduced in hypoxic HPAECs and PAs, the levels of $\mathrm{BH}_{2}$ were increased under these conditions, resulting in a decreased $\mathrm{BH}_{4} / \mathrm{BH}_{2}$ ratio (Fig. 1C). However, total biopterin levels were not significantly changed in hypoxia, suggesting that hypoxia did not affect biopterin synthesis (Fig. 1D).

\section{FA increases DHFR levels and $\mathrm{BH}_{4}$ bioavailability under hypoxia}

Since hypoxia disrupted the balance between $\mathrm{BH}_{4}$ and $\mathrm{BH}_{2}$, but did not affect overall biopterin levels, we hypothesized that recycling of $\mathrm{BH}_{4}$ from $\mathrm{BH}_{2}$ rather than de novo $\mathrm{BH}_{4}$ synthesis might be affected by hypoxia. Since the conversion of $\mathrm{BH}_{2}$ to $\mathrm{BH}_{4}$ is mediated by DHFR, we determined DHFR protein levels in HPAECs. Compared with normoxia, DHFR protein levels as well as mRNA levels were reduced under hypoxia (Fig. 2A, B). These findings suggest that the decrease in $\mathrm{BH}_{4}$ and the increase in $\mathrm{BH}_{2}$ observed under hypoxic conditions might be related to a decreased recycling capacity due to lowered DHFR levels. 

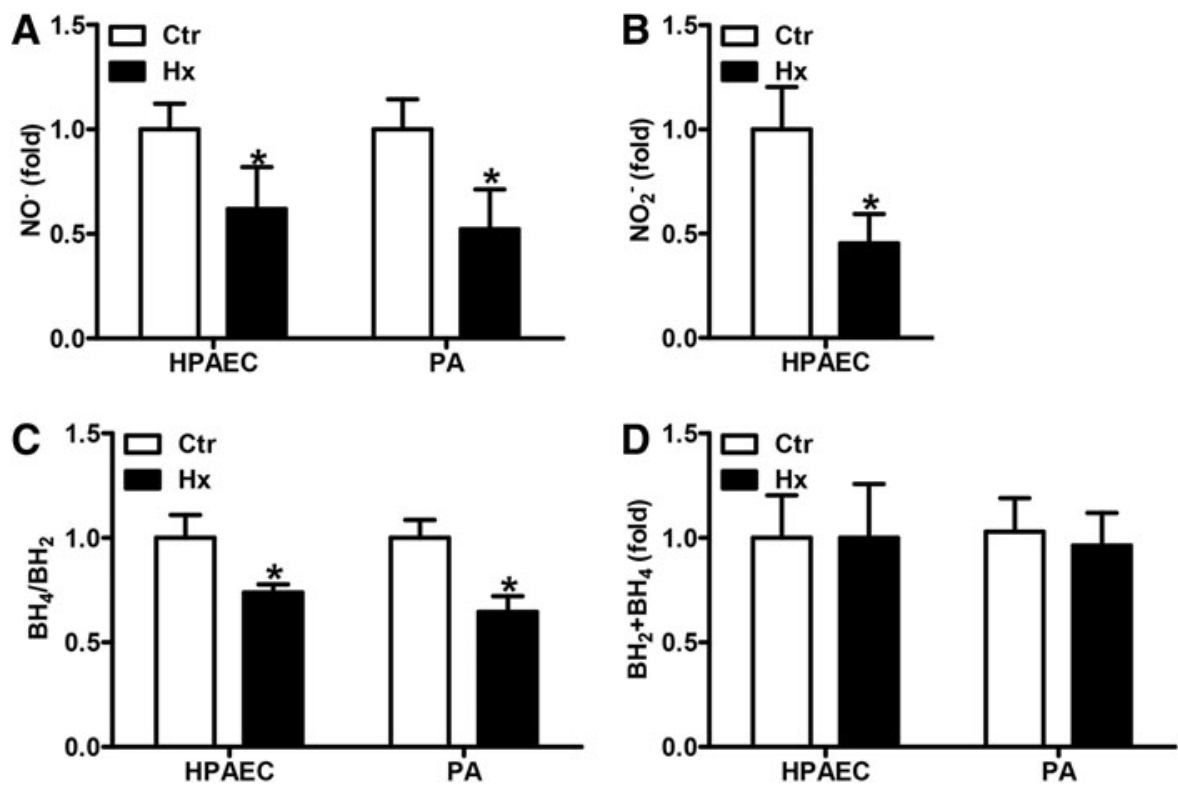

FIG. 1. Hypoxia decreases NO availability. (A-D) HPAECs or isolated murine PAs were incubated in hypoxic (1\% oxygen, $\mathrm{Hx}$ ) or normoxic conditions $(\mathrm{Ctr})$ for $24 \mathrm{~h}$. (A) NO levels were measured by EPR using iron $\left(2^{+}\right)$-diethyldithiocarbamic acid $\left[\mathrm{Fe}\left(2^{+}\right)(\mathrm{DETC})\right]$ complex as an NO radical-specific spin probe. Normoxic levels were set equal to $1[n=4 ; * p<0.05,(1-\beta)$ $\geq 0.897$ vs. Ctr]. (B) Nitrite levels were determined in the supernatant of HPAECs by HPLC. Normoxic levels were set equal to 1 $\left[n=3 ; * p<0.05,(1-\beta) \geq 0.969\right.$ vs. Ctr). (C) $\mathrm{BH}_{4}$ and $\mathrm{BH}_{2}$ levels were measured in cell and tissue lysates by HPLC. Normoxic levels were set equal to $1\left[n=5 ; * p<0.05,(1-\beta) \geq 0.999 v s\right.$. Ctr]. (D) The sum of $\mathrm{BH}_{4}$ and $\mathrm{BH}_{2}$ levels in HPAECs and PAs was calculated. $\mathrm{BH}_{2}$, dihydrobiopterin; $\mathrm{BH}_{4}$, tetrahydrobiopterin; EPR, electron paramagnetic resonance; HPAEC, Human pulmonary artery endothelial cells; HPLC, high-pressure liquid chromatography; NO, nitric oxide; PAs, pulmonary arteries.

FA has been described to increase the levels of DHFR in the systemic vasculature (25). To evaluate whether FA could modulate DHFR levels in our setting, HPAECs were supplemented with FA $(50 \mu M)$ at a concentration previously shown to induce DHFR (25). Subsequent exposure to hypoxia for $24 \mathrm{~h}$ showed that FA supplementation not only restored hypoxic DHFR protein levels but also enhanced normoxic DHFR protein levels (Fig. 2A). In addition, FA enhanced DHFR mRNA levels under normoxic and hypoxic conditions (Fig. 2B). Application of actinomycin D to normoxic or hypoxic HPAECs treated with FA blunted FAmediated induction of DHFR protein levels, indicating that FA promotes transcription of DHFR (Fig. 2A).

We next determined the effects of $\mathrm{FA}$ on $\mathrm{BH}_{4}$ levels. Under hypoxia, the $\mathrm{BH}_{4} / \mathrm{BH}_{2}$ ratio was restored to normoxic levels in HPAECs and PAs treated with FA, while it was even further increased under normoxic conditions (Fig. 2C, D). Upon brief exposure to normoxia following hypoxia simulating hypoxiareoxygenation conditions, the $\mathrm{BH}_{4} / \mathrm{BH}_{2}$ ratio remained low. Similar to the situation with hypoxia, FA restored the $\mathrm{BH}_{4} / \mathrm{BH}_{2}$ ratio to normoxic levels (Fig. 2C). However, FA did not affect total biopterin levels under normoxia or hypoxia (Fig. 2E, F), indicating that it did not act via de novo biopterin synthesis.

\section{FA increases NO bioavailability under hypoxia}

We next determined the effects of FA on NO availability. In HPAECs, FA dose dependently increased NO levels under hypoxia (Fig. 3A, Supplementary Fig. S1; Supplementary Data are available online at www.liebertpub.com/ars). Since $50 \mu M$ FA significantly restored hypoxic NO levels to normoxic levels, while higher concentrations did not show ad- ditional beneficial effects, we performed all the following in vitro studies at $50 \mu M$ concentration. In line, $50 \mu M$ FA also efficiently restored hypoxic NO levels in PAs (Fig. 3B) and hypoxic nitrite levels in HPAECs to normoxic levels (Fig. 3C). Similar to the situation with $\mathrm{BH}_{4}$, NO levels remained low under hypoxia-reoxygenation conditions in HPAECs and were partially restored by FA (Fig. 3A).

To confirm that modulation of DHFR levels was indeed involved in the control of NO levels under hypoxia and FA treatment, DHFR levels were downregulated by an siRNA approach (Fig. 3D). While downregulation of DHFR levels did not affect NO levels under normoxic conditions, it further decreased hypoxic NO levels (Fig. 3E). However, induction of NO levels by FA was blunted in normoxia and hypoxia in DHFR-depleted HPAECs, indicating that FA acts via DHFR to improve NO bioavailability. In contrast, supplementation with L-arginine, which has been indicated to also recouple eNOS (26), only increased hypoxic NO levels at high concentrations (Supplementary Fig. S2).

Since FA has been previously reported to modulate the phosphorylation status of eNOS (65), the levels of Ser1177phosphorylated eNOS, which renders the enzyme active, and of Thr495-phosphorylated eNOS, which results in inactivation of the enzyme, were determined. In HPAECs, phosphorylation at both sites was increased under hypoxia (Fig. 3F). FA increased the levels of Ser1177-phosphorylated eNOS under normoxic conditions, although it did not further increase Ser1177-phosphorylated eNOS levels under hypoxia in HPAECs. In contrast, FA rather decreased eNOS phosphorylation at Thr495 under normoxic and hypoxic conditions (Fig. 3F). However, FA had no effect on eNOS protein levels under normoxia or hypoxia (Fig. 3F). 
FIG. 2. FA restores DHFR expression and the $\mathrm{BH} 4 / \mathrm{BH} 2$ balance under hypoxia. (A) HPAECs were incubated in hypoxia $(1 \%$ oxygen, $\mathrm{Hx}$ ) or normoxia (Ctr) for $24 \mathrm{~h}$ in the presence or absence of FA $(50 \mu M)$ with and without ActD $(1 \mu M)$. Western blot analysis was performed with an antibody against DHFR. $\beta$-actin served as loading control. Normoxic levels were set equal to $1[n=4 ; * p<0.05$, (1$\beta) \geq 0.965$ vs. $\mathrm{CtrCtr} ;{ }^{\#} p<0.05,(1-$ $\beta)=1$ vs. HxCtr; ${ }^{\S} p<0.05,(1-\beta)$ $\geq 0.858$ vs. respective $\mathrm{FA}]$. (B) DHFR mRNA levels were determined by RT-qPCR in normoxic (Ctr) or hypoxic (Hx) HPAECs. $18 \mathrm{~S}$ rRNA served as loading control. Normoxic levels were set equal to $1[n=4 ; * p<0.05,(1-\beta)$ $\geq 0.95$ vs. CtrCtr; ${ }^{\#} p<0.05$, (1$\beta)=1$ vs. HxCtr]. (C) HPAECs or (D) isolated murine PAs were incubated in hypoxic or normoxic conditions for $24 \mathrm{~h}$ in the presence or absence of FA. $\mathrm{BH}_{4}$ and $\mathrm{BH}_{2}$ levels were measured in cell and tissue lysates by HPLC under hypoxic or reoxygenated $(\mathrm{ReOx})$ conditions $[n=5 ; * p<0.05,(1-\beta)$ $\geq 0.963$ vs. $\mathrm{CtrCtr} ;{ }^{\#} p<0.05,(1-\beta)$ $\geq 0.942$ vs. HxCtr, ${ }^{\S} p<0.05$, (1$\beta)=1$ vs. $\mathrm{ReOxCtr]}$. The sum of $\mathrm{BH}_{4}$ and $\mathrm{BH}_{2}$ levels was calculated (E) in HPAECs and (F) in murine PAs. ActD, actinomycin D; DHFR, dihydrofolate reductase; FA, folic acid; RT-qPCR, real-time quantitative polymerase chain reaction.
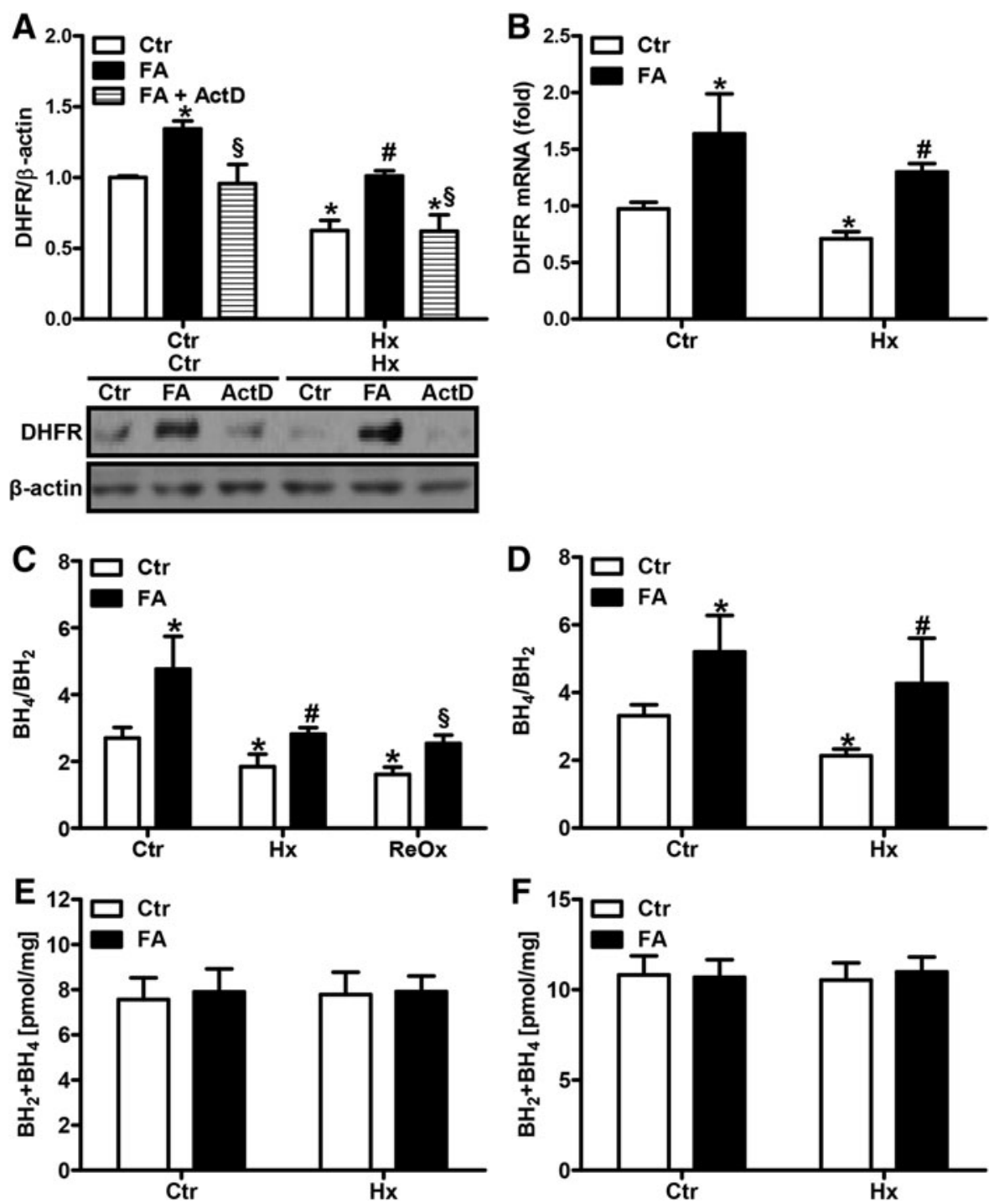

The findings that FA is also able to increase NO levels under normoxic conditions due to enhanced $\mathrm{BH}_{4}$ availability by inducing DHFR-dependent recycling capacity and by modulation of eNOS phosphorylation suggest that basal NO bioavailability in our experimental setup might be limited by insufficient FA supply. In support, FA was able to improve endothelium-dependent relaxation of isolated PAs in response to acetylcholine, further indicating that FA can improve NO bioavailability (Supplementary Fig. S3).

\section{Superoxide levels are decreased under hypoxia}

Reduced $\mathrm{BH}_{4}$ levels have been previously associated with uncoupling of NOS, which leads to the formation of superoxide instead of NO. We therefore determined superoxide production in HPAECs and PAs under normoxia and hypoxia by EPR. To this end, hypoxic cells or vessels were harvested and prepared for superoxide measurements under hypoxic conditions using a hypoxic workbench. Measurements were performed in an airtight capillary, thus preventing any reoxygenation step during sample handling. Under these conditions, cells and tissues exposed for $24 \mathrm{~h}$ to hypoxia showed decreased superoxide production compared with normoxia (Fig. 4A, B).
In contrast, when sample harvesting and preparation were performed under normoxic conditions following $24 \mathrm{~h}$ of hypoxia, superoxide production was even more increased than under normoxia (Fig. 4A, B). These findings indicate that even short-term exposure to normoxia during sample preparation is sufficient to induce a reoxygenation effect.

\section{eNOS is uncoupled under hypoxic conditions}

To evaluate whether uncoupled eNOS contributes to superoxide production under normoxia or hypoxia, HPAECs and PAs were treated with the NOS inhibitor, L-(G)-nitroL-arginine methyl ester (L-NAME), before superoxide measurements. While L-NAME did not affect normoxic or reoxygenated superoxide levels, it significantly decreased hypoxic superoxide production (Fig. 4A, B), indicating that uncoupling of eNOS contributed to superoxide production under hypoxic conditions. In line, hypoxia increased the eNOS monomer/dimer ratio in HPAECs, further supporting the view that hypoxia can uncouple eNOS (Fig. 4C). Increased eNOS monomer formation was also observed in pulmonary and systemic vessels, further confirming that eNOS is uncoupled under hypoxia (Supplementary Fig. S4). 

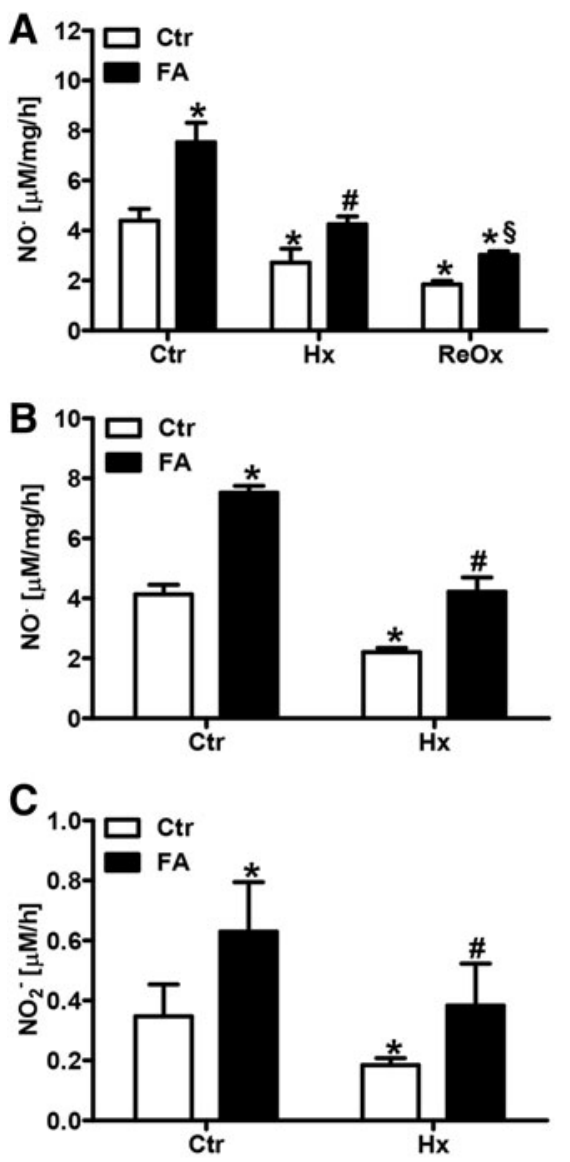
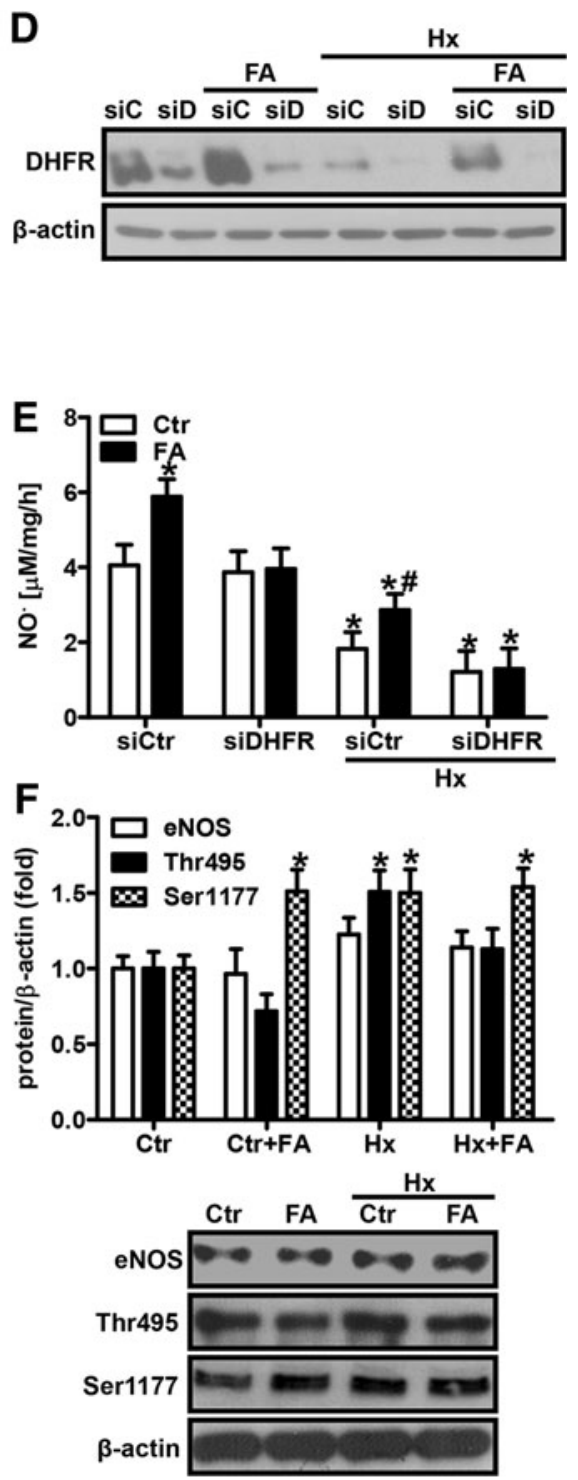

FIG. 3. FA prevents decreased NO bioavailability under hypoxia. (A) HPAECs or (B) isolated murine PAs were incubated in hypoxia ( $1 \%$ oxygen, $\mathrm{Hx}$ ) or normoxia (Ctr) for $24 \mathrm{~h}$ in the presence or absence of FA $(50 \mu M)$. NO levels were measured by EPR using $\left[\mathrm{Fe}\left(2^{+}\right)(\mathrm{DETC})\right]$ complex under hypoxic or reoxygenated conditions (ReOx) $[n=4$; $* p<0.05,(1-\beta) \geq 0.997$ vs. CtrCtr; $\#_{p}<0.05,(1-\beta) \geq 0.997$ vs. HxCtr; ${ }^{8} p<0.05,(1-\beta)=1$ vs. ReOxCtr]. (C) Nitrite levels were determined in the supernatant of HPAECs by HPLC $[n=3 ; \quad * p<0.05, \quad(1-\beta)$ $\geq 0.822$ vs. CtrCtr; ${ }^{\sharp} p<0.05,(1-\beta)$ $\geq 0.8$ vs. HxCtr]. (D, E) HPAECs were transfected with siRNA against DHFR (siD/siDHFR) or scrambled siRNA (siC/siCtr) and exposed to hypoxia in the presence or absence of FA. (D) Western blot analysis was performed with an antibody against DHFR. $\beta$-actin served as loading control. (E) NO levels were measured by EPR $[n=3 ; * p<0.05,(1-\beta)$ $\geq 0.84$ vs. CtrsiCtr; ${ }^{p} p<0.05,(1-\beta)$ $\geq 0.835 v s$. HxsiCtr). (F) Western blot analyses were performed in HPAECs using antibodies against eNOS and phosphorylated eNOS (Ser-1177, Thr-495). $\beta$-actin served as a loading control. Normoxic levels were set equal to $1 \quad(n=3 ; * p<0.05,(1-\beta)$ $\geq 0.801$ vs. CtrCtr). eNOS, endothelial nitric oxide synthase.
Recoupling of eNOS by FA should not only result in increased NO levels but also in reduced superoxide levels. In fact, in HPAECs, hypoxic and reoxygenated superoxide levels were decreased in the presence of FA, although this effect was less pronounced in PAs (Fig. 4A, B). In line, the eNOS monomer/ dimer ratio under hypoxia was diminished upon treatment with FA, further indicating recoupling of eNOS (Fig. 4C).

To evaluate the contribution of other sources of reactive oxygen species (ROS) under these conditions, HPAECs were pretreated with apocynin, an antioxidant, 2-thenoyltrifluoroacetone (TTFA), a mitochondrial complex II inhibitor, or rotenone, a complex I inhibitor. While none of the inhibitors significantly affected normoxic superoxide levels, apocynin decreased hypoxic superoxide levels similar to the situation with L-NAME (Fig. 4D).

Since NADPH oxidases have been suggested to play a role in the pulmonary vascular response to hypoxia (43), HPAECs were treated with GKT-137831, which has been described to inhibit NADPH oxidases (1). GKT-137831 treatment decreased normoxic and hypoxic ROS levels (Fig. 4E). These findings indicate that NADPH oxidases also contribute to maintain ROS levels under hypoxia as has been described previously (16), while mitochondrial ROS might play a minor role under these conditions. In line, hypoxia induced NOX4 levels in HPAECs, while FA did not affect NOX4 levels, suggesting that the contribution of NADPH oxidases is independent of NO signaling (Fig. 4F).

Interestingly, under reoxygenated conditions, apocynin and GKT-137831 reduced superoxide production (Fig. 4D, E), while mitochondrial inhibitors similar to L-NAME pretreatment were not as effective, indicating that NADPH oxidases are a major source of ROS under reoxygenated conditions.

\section{FA improves NO bioavailability under chronic hypoxia in vivo}

In a next step, we evaluated the levels of NO in vivo in mice exposed for 2 weeks to hypoxia ( $10 \%$ oxygen) by determining NO-hemoglobin levels by EPR (Fig. 5A). Systemic NOhemoglobin levels were decreased in chronic hypoxic mice compared with normoxic mice (Fig. 5A). In line, the ratio of plasma $\mathrm{BH}_{4} / \mathrm{BH}_{2}$ was lower in hypoxic than in normoxic mice 

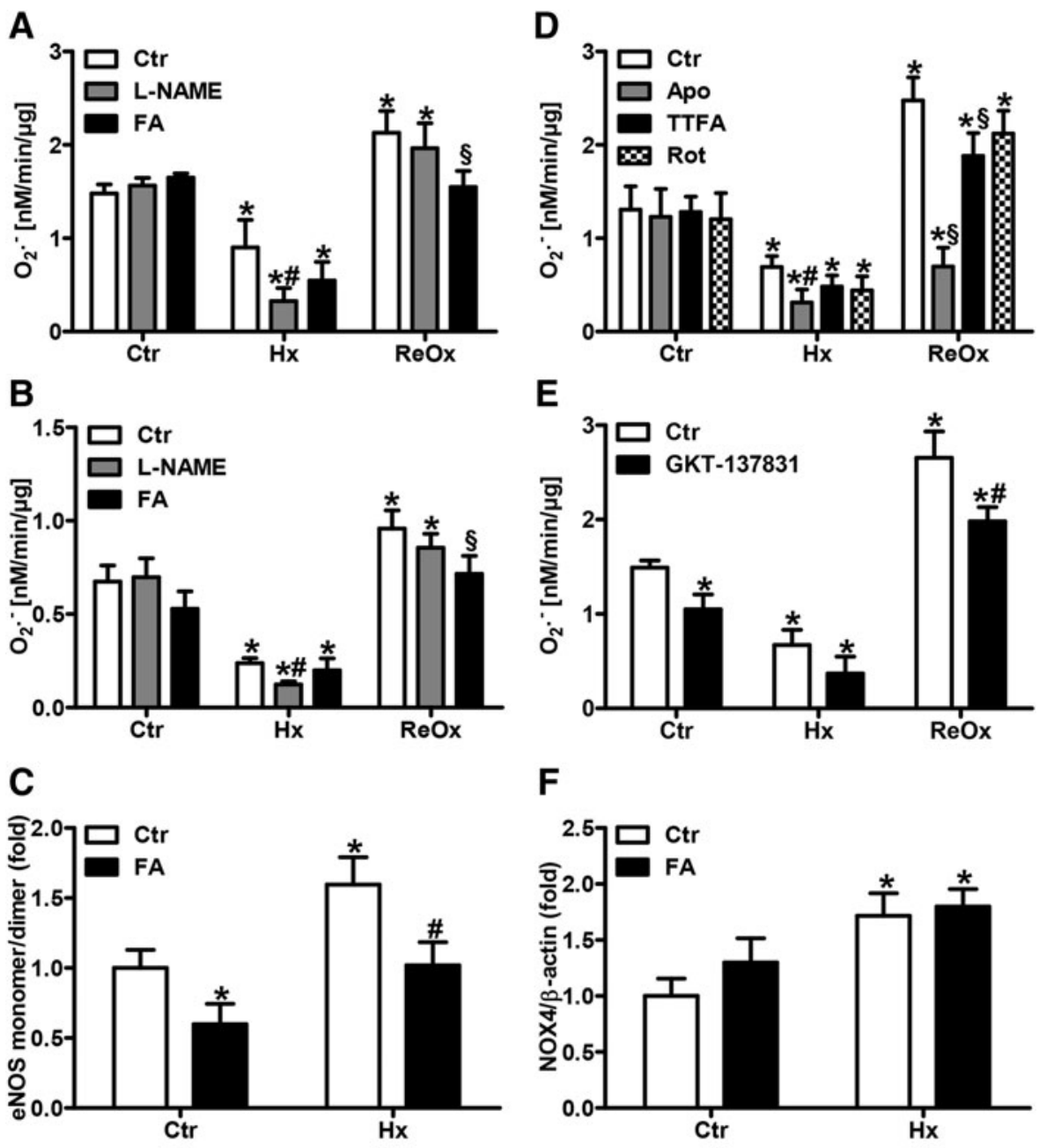

$\mathbf{F}$
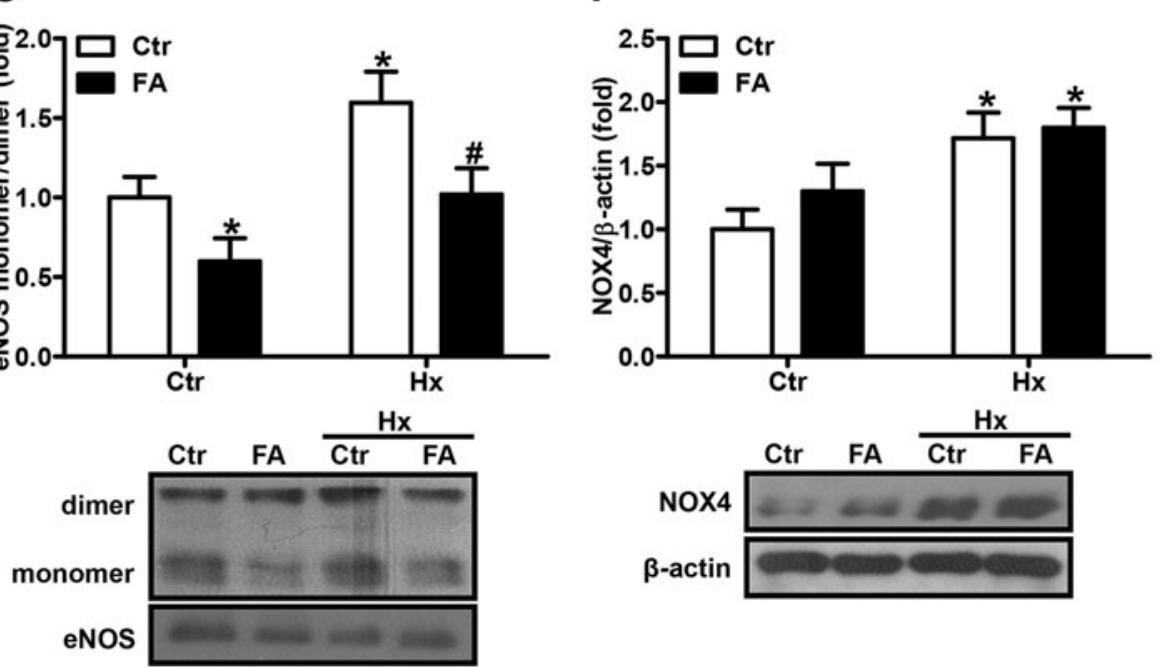

FIG. 4. Uncoupled eNOS contributes to superoxide production under hypoxia. (A) HPAECs or (B) isolated murine PAs were incubated under normoxic (Ctr) or hypoxic $(\mathrm{Hx})$ conditions for $24 \mathrm{~h}$ in the presence or absence of the NO synthase inhibitor, L-(G)-nitro-L-arginine methyl ester (L-NAME, $300 \mu M)$, and/or FA $(50 \mu M)$. The superoxide production rate was measured by EPR using $\mathrm{CMH}$ as a spin probe under complete hypoxic ( $\mathrm{Hx}$ ) or normoxic following hypoxic conditions $(\operatorname{ReOx})\left[n=5 ;{ }^{*} p<0.05,(1-\beta) \geq 0.943\right.$ vs. $\mathrm{CtrCtr} ;{ }^{\#} p<0.05,(1-\beta) \geq 0.977 v s$. $\mathrm{HxCtr} ;{ }^{\S} p<0.05,(1-\beta)$ $\geq 0.976$ vs. ReOxCtr]. (C) eNOS monomer formation was determined in HPAECs by nondenaturing gel analysis, followed by Western blot with an antibody against eNOS. The monomer/dimer ratio was calculated. Normoxic levels were set equal to $1\left[n=3 ; * p<0.05,(1-\beta) \geq 0.946 v s\right.$. CtrCtr; ${ }^{*} p<0.05,(1-\beta) \geq 0.975 v s$. HxCtr]. (D) HPAECs were incubated under normoxic or hypoxic conditions for $24 \mathrm{~h}$ in the presence or absence of the antioxidant, Apo $(100 \mu M)$, or inhibitors of mitochondrial complex II, TTFA $(100 \mu M)$, or complex I, Rot $(100 \mu M)$. The superoxide production rate was measured as above $\left[n=3 ;{ }^{*} p<0.05,(1-\beta) \geq 0.83 v s\right.$. CtrCtr; ${ }^{\#} p<0.05,(1-\beta) \geq 0.949 v s$. HxCtr; ${ }^{\S} p<0.05,(1-\beta) \geq 0.833 v s$. ReOxCtr]. (E) HPAECs were incubated under normoxic or hypoxic conditions for $24 \mathrm{~h}$ in the presence or absence of GKT$137831(50 \mu M)$. The superoxide production rate was measured as above $[n=3 ; * p<0.05,(1-\beta) \geq 0.992 v s$. CtrCtr; ${ }^{\#} p<0.05,(1-\beta) \geq 0.957$ vs. ReOxCtr]. (F) Western blot analyses were performed in HPAECs with an antibody against NOX4. $\beta$-actin served as a loading control. Normoxic levels were set equal to $1[n=3 ; * p<0.05,(1-\beta) \geq 0.998 v s$. CtrCtr]. Apo, apocynin; CMH, 1-hydroxy-methoxycarbonyl-2,2,5,5-tetramethyl-pyrrolidine hydrochloride; Rot, rotenone; TTFA, 2-thenoyltrifluoroacetone. 

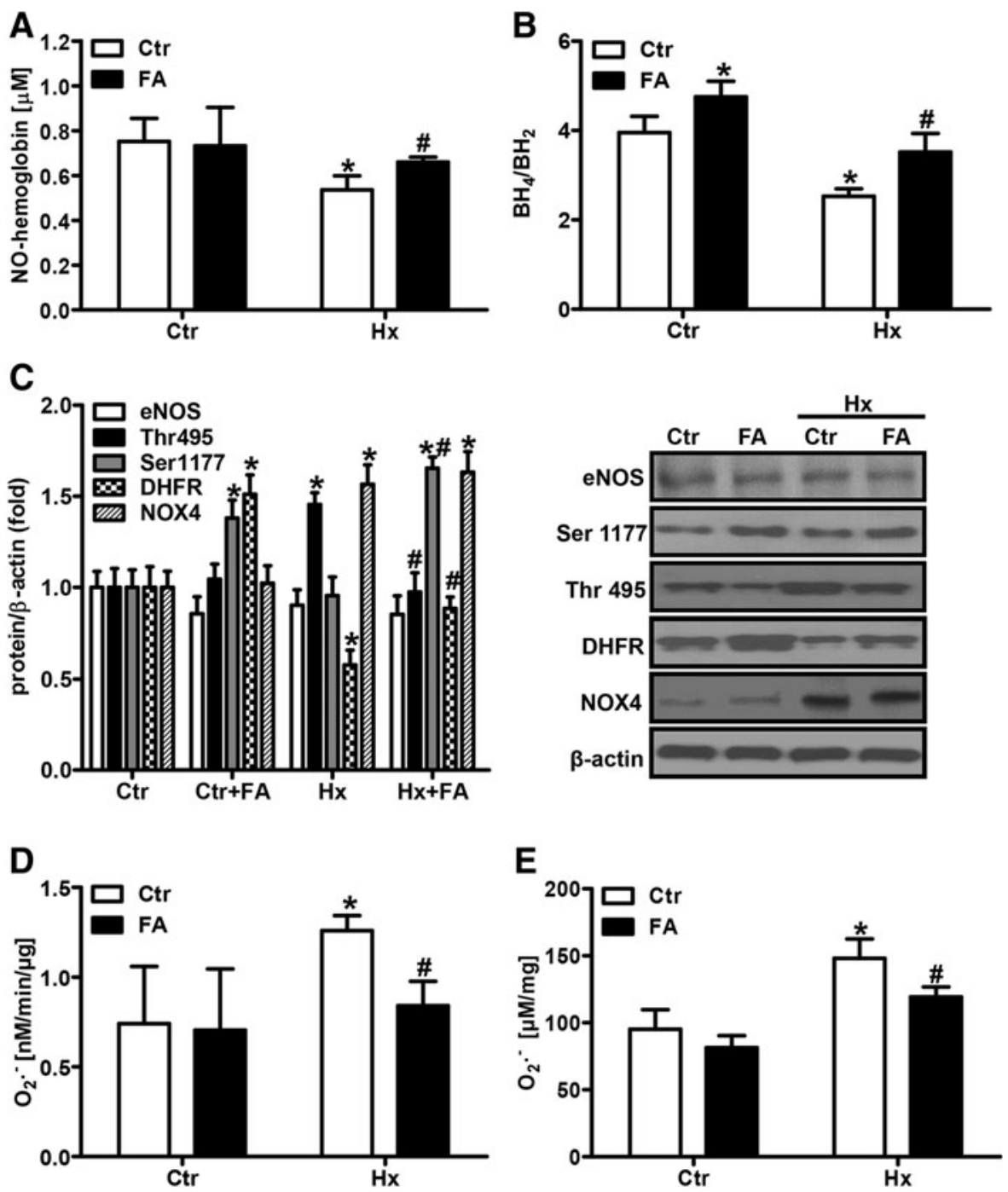

FIG. 5. FA prevents the decrease in NO bioavailability in chronic hypoxic mice. Mice were exposed for 2 weeks to hypoxia (10\% oxygen, $\mathrm{Hx}$ ) or normoxia (Ctr) with or without supplementation of FA $(5 \mathrm{mg} / \mathrm{kg} /$ day). (A) NO-hemoglobin levels were measured in red blood cell fractions by $\operatorname{EPR}[n=5 ; * p<0.05$, $(1-\beta) \geq 0.971$ vs. CtrCtr; ${ }^{\#} p<0.05$, $(1-\beta) \geq 0.984$ vs. $\mathrm{HxCtr}$. (B) $\mathrm{BH}_{4}$ and $\mathrm{BH}_{2}$ levels were measured in plasma using HPLC, and the $\mathrm{BH}_{4} /$ $\mathrm{BH}_{2}$ ratio was determined $[n=6$; ${ }^{*} p<0.05,(1-\beta) \geq 0.97$ vs. CtrCtr; $\#_{p}<0.05,(1-\beta)=1$ vs. HxCtr]. (C) Expression levels of eNOS, Ser1177and Thr495-phosphorylated eNOS, DHFR, and NOX4 were analyzed in lung tissue lysates by Western blotting. $\beta$-actin served as a loading control $[n=3 ; * p<0.05,(1-\beta) \geq 0.8$ vs. CtrCtr; ${ }^{*} p<0.05,(1-\beta) \geq 0.85$ vs. $\mathrm{HxCtr}$. (D) PAs were isolated and superoxide production was measured by EPR $\left[n=6 ;{ }^{*} p<0.05, \quad(1-\beta)\right.$ $\geq 0.989$ vs. CtrCtr; ${ }^{\#} p<0.05$, (1$\beta)=1$ vs. $\mathrm{HxCtr}]$. (E) Whole lung extracts were incubated with DHE $(10 \mu M)$, and ROS levels were determined by measuring 2hydroxyethidium fluorescence by HPLC $\quad[n=6 ; \quad * p<0.05, \quad(1-\beta)$ $\geq 0.995$ vs. CtrCtr; ${ }^{\#} p<0.05,(1-\beta)$ $\geq 0.897$ vs. HxCtr]. DHE, dihydroethidium; ROS, reactive oxygen species.

(Fig. 5B). When mice were orally supplemented with FA (5 mg/ $\mathrm{kg} /$ day) during exposure to hypoxia, NO-hemoglobin levels and plasma $\mathrm{BH}_{4}$ availability were restored to normoxic levels (Fig. 5A, B). Subsequently, decreased pulmonary DHFR levels in hypoxic lungs were restored in FA-treated animals (Fig. 5C).

Similar to the situation in vitro, pulmonary eNOS protein levels were neither affected by hypoxia nor by FA (Fig. 5C). However, the levels of Ser1177-phosphorylated eNOS were increased by FA under normoxia and hypoxia (Fig. 5C), while the levels of Thr495-phosphorylated eNOS were decreased (Fig. 5C), indicating that FA improves NO bioavailability in vivo by several mechanisms.

\section{FA decreases ROS levels following chronic hypoxia in vivo}

To evaluate the levels of ROS in chronic hypoxic mice, PAs were isolated from normoxic and hypoxic mice under normoxic conditions simulating a reoxygenated state and superoxide levels were determined by EPR. Compared with vessels from normoxic mice, vessels from chronic hypoxic mice showed elevated superoxide production (Fig. 5D) similar to the in vitro situation of hypoxia-reoxygenation. ROS levels were also determined in lung tissues by HPLC using dihy- droethidium (DHE) as a probe. Similar to the results in PAs, ROS levels were increased in lungs derived from hypoxic mice compared with normoxic lungs (Fig. 5E). Treatment with FA significantly decreased ROS levels in PAs and lung tissues derived from chronic hypoxic mice (Fig. 5D, E). These findings are similar to the situation when superoxide levels of hypoxic HPAECs were determined under normoxic conditions.

As described previously (16), and suggested by our in vitro data, NADPH oxidases might contribute to the increased levels of ROS upon reoxygenation. In line, levels of the NADPH oxidase subunit, NOX4, were substantially increased in lung tissues from hypoxic mice compared with normoxic mice (Fig. 5C). This supports the notion that induction of NADPH oxidases by hypoxia primes for increased ROS production under reoxygenated conditions (16). However, FA treatment did not affect NOX4 levels, ruling out that the reduction of ROS levels observed in chronic hypoxic mice treated with FA was due to downregulation of NOX4 (Fig. 5C).

\section{FA protects against hypoxia-induced $R V H$, right ventricular pressure increase, and PVR}

In mice exposed to chronic hypoxia, right ventricular mass increased as was estimated by determination of the angle 
FIG. 6. FA decreases hypoxiainduced right ventricular hypertrophy, RVP increase, and pulmonary vascular remodeling. Mice were placed for 2 weeks under hypoxia $(10 \%$ oxygen, $\mathrm{Hx})$ or normoxia $(\mathrm{Nx} / \mathrm{Ctr})$ with or without supplementation of FA $(5 \mathrm{mg} / \mathrm{kg} /$ day). (A) RV size was macroscopically estimated by determining the angle between the RIV and RDM. (B) Gross heart morphology was macroscopically observed. (C) FFPE heart sections were stained with Giemsa. (D) FFPE lung sections were stained with an antibody against $\alpha$-SMA. Bar $100 \mu \mathrm{m}$; arrows indicate $\alpha$-SMA-positive vessels. (E) The (RV) was separated from the $L V$ and $S$ and weighed. The RV/ $\mathrm{LV}+\mathrm{S}$ ratio was determined $[n=5$; $* p<0.05, \quad(1-\beta)=1 \quad$ vs. $\quad \mathrm{CtrCtr}$ $\#_{p}<0.05,(1-\beta) \geq 0.999$ vs. HxCtr]. (F) RVP was determined hemodynamically $[n=5 ; * p<0.05,(1-\beta)$ $\geq 0.966$ vs. CtrCtr; ${ }^{\#} p<0.05,(1-\beta)$ $\geq 0.8$ vs. HxCtr]. (G) $\alpha$-SMApositive small- and medium-sized arterioles $(<80 \mu \mathrm{m})$ were counted and related to the total number of arterioles of the same diameter $[n=6 ; \quad * p<0.05, \quad(1-\beta)=1 \quad v s$. CtrCtr; ${ }^{\#} p<0.05, \quad(1-\beta)=1 \quad v s$. $\mathrm{HxCtr}$. $\alpha$-SMA, $\alpha$-smooth muscle actin; FFPE, formalin-fixed paraffin-embedded; LV, left ventricle; RDM, right marginal coronary artery; RIV, left descending interventricular artery; RV, right ventricle; RVP, right ventricular pressure; $\mathrm{S}$, septum. To see this illustration in color, the reader is referred to the web version of this article at www.liebertonline.com/ars.
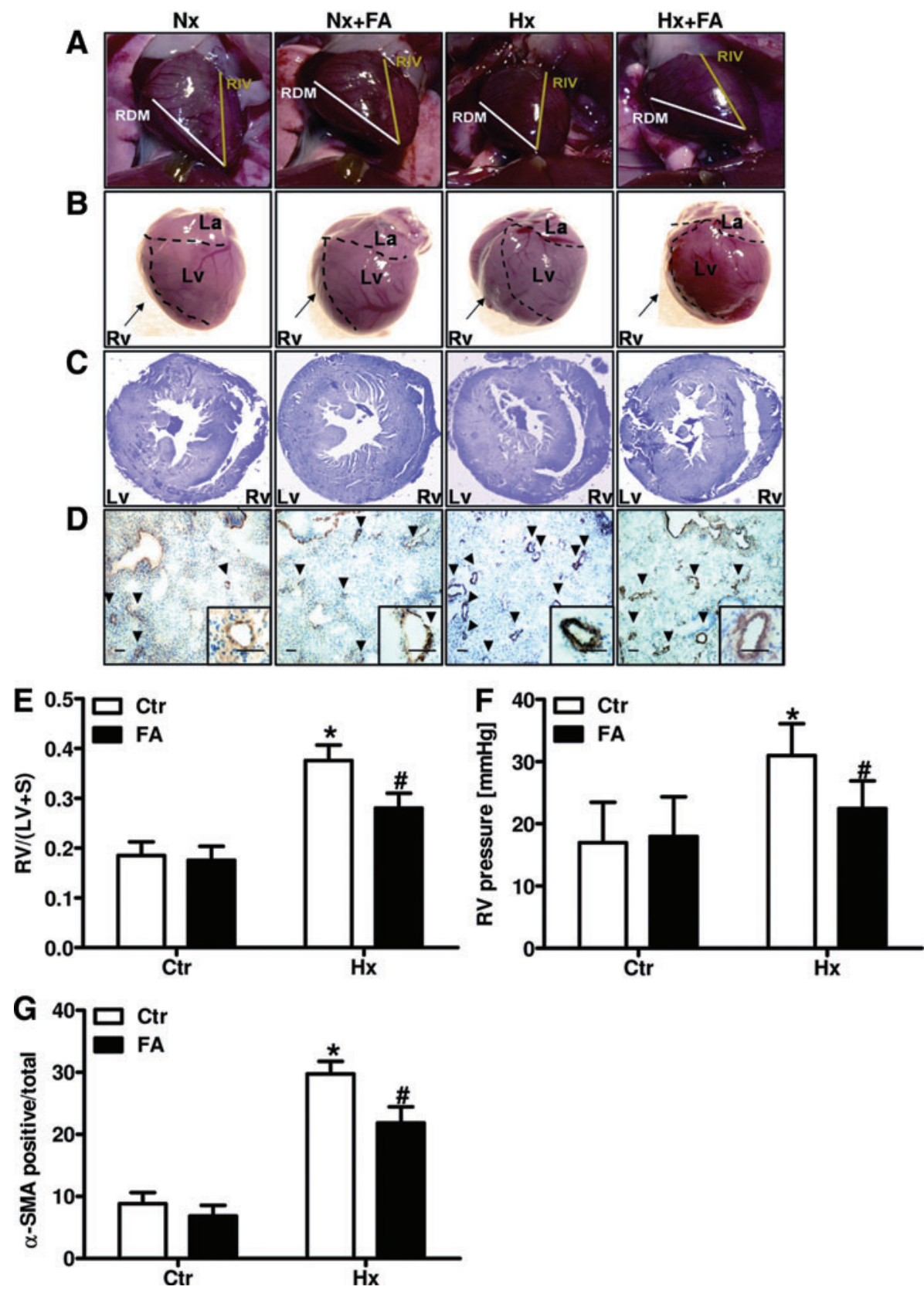

between the left descending interventricular artery (RIV) and the right marginal coronary artery (RDM). Compared with $44^{\circ}$ in normoxic hearts, this angle was $59^{\circ}$ in hypoxic hearts (Fig. 6A, B). In line, sections derived from formalin-fixed paraffin-embedded (FFPE) hearts demonstrated an increase in right ventricular wall thickness in hypoxic mice compared with normoxic control mice (Fig. 6C). In addition, the ratio between right ventricular weight and left ventricular and interseptal weight (Fulton Index) was increased in hypoxic compared with normoxic mice (Fig. 6E), indicating the development of RVH in chronic hypoxic mice. In line, hemodynamic measurements showed increased right ventricular pressure (RVP) in hypoxic mice (Fig. 6F).

Furthermore, staining of FFPE lung sections with an antibody specific for alpha-smooth muscle actin ( $\alpha$-SMA) showed an increased number of muscularized small vessels (diameter $<80 \mu \mathrm{m}$ ) in lungs from hypoxic mice compared with normoxic mice, indicating PVR (Fig. 6D, G).

Treatment with FA reduced $\mathrm{RVH}$ as indicated by a reduction of the angle between RIV and RDM to normoxic values in hearts derived from hypoxic mice treated with FA (Fig. 6A, B). Under normoxic conditions, however, FA treatment had no effect on the size of the right ventricle (RV) (Fig. 6A, B). Similarly, FA treatment reduced hypoxia-induced thickening of the right ventricular wall and RV weight (Fig. 6C, E) and blunted the increased RVP in chronic hypoxic mice (Fig. 6F). In addition, FA treatment decreased the number of small muscularized vessels in hypoxic lungs (Fig. 6D, G). Collectively, these data show that treatment with FA protects against the development of $\mathrm{PH}$ by reducing PVR, RVP, and $\mathrm{RVH}$ in response to chronic hypoxia. 


\section{Discussion}

In this study, we demonstrate that FA protects mice against hypoxia-induced RVH, RVP increase, and PVR — hallmarks of $\mathrm{PH}(\mathrm{PH})$ - by restoring DHFR expression, improving the capacity to recycle $\mathrm{BH}_{2}$ to $\mathrm{BH}_{4}$, and subsequently increasing NO bioavailability.

Our data indicate that under hypoxic conditions, NO bioavailability is not only decreased in HPAECs and isolated PAs but also in vivo in chronic hypoxic mice with $\mathrm{PH}$, although the levels of eNOS remained unchanged.

In contrast, hypoxia has been reported to increase eNOS expression, often accompanied by increased NO bioavailability, in endothelial cells and in the in vivo situation in rats and mice $(9,32,38,61)$. While the reasons for these controversial data are not clear, they might relate to differences in model systems, timing, and severity of hypoxia, as well as to variations in secondary effects associated with hypoxia in particular in the in vivo situation (28). However, in line with our observations, there is increasing evidence that hypoxia limits NO bioavailability in vitro and in vivo $(20,28,37,50,67)$. Similar to our study, decreased NO levels were not always related to decreased levels of eNOS. This indicates that other mechanisms apart from modulation of eNOS expression contribute to the adaptation of NO metabolism under hypoxia (73).

In our study, decreased NO bioavailability was accompanied by a disruption in $\mathrm{BH}_{4}$ homeostasis with decreased levels of $\mathrm{BH}_{4}$ and increased levels of $\mathrm{BH}_{2}$ in vitro and in vivo.

Decreased $\mathrm{BH}_{4}$ levels have been considered to be an important determinant of a dysfunctional uncoupled eNOS, which generates superoxide instead of $\operatorname{NO}(5,13)$. In fact, application of the NOS inhibitor, L-NAME, decreased superoxide generation under hypoxia, suggesting an uncoupling of eNOS under these conditions. Similarly, hypoxia increased monomer formation of eNOS as another indication of uncoupling. Uncoupled eNOS has been associated with various cardiovascular disorders, including PH $(26,33)$. In support of our findings, decreased $\mathrm{BH}_{4}$ levels in hypoxic in vivo models $(23,36)$ have been recently reported, although the levels of superoxide or other ROS have not been determined in these studies. While eNOS uncoupling has been described in a situation of hypoxia-reoxygenation in endothelial cells unlike in our study (15), the contribution of uncoupled eNOS to ROS levels under hypoxia has not been clearly demonstrated to date.

In fact, the role of ROS in the hypoxic response has been a matter of debate and conflicting data exist regarding whether there is an increase or a decrease in ROS levels under hypoxia (27). In our study, using a setup where sample handling and superoxide measurements were performed under hypoxic conditions, superoxide generation was found to be lower under hypoxic than under normoxic conditions. However, when superoxide measurements were performed under normoxia following exposure to hypoxia, thus mimicking short-term hypoxia-reoxygenation, superoxide levels were increased, even exceeding basal normoxic levels. These findings support previous observations that ROS levels are increased under hypoxia-reoxygenation conditions (16). Since it was sufficient to expose hypoxic HPAECs or PAs for a short time period to normoxia to increase superoxide generation, these observations might explain some of the divergent results concerning ROS levels under hypoxia (27).
In support, increased ROS levels were measured in pulmonary vessels and lung tissues derived from chronic hypoxic mice. In line, elevated ROS levels in lungs and vessels from chronic hypoxic animals have been described previously $(24,41,42)$. However, since mouse handling as well as tissue preparation following chronic hypoxia was performed in normoxia, it is likely that the increase in ROS was induced by reoxygenation rather than by hypoxia as demonstrated by our in vitro studies. The assumption that ROS levels are increased in mice exposed to chronic hypoxia $(24,41)$ might thus not reflect the real situation in vivo, and reoxygenation effects need to be considered. Thus, although beyond the scope of this study, further studies are required to show whether ROS levels will still be elevated in chronic hypoxic mouse tissues when mouse handling, sample preparation, and ROS measurements are performed under fully hypoxic conditions.

In contrast to the hypoxic setting, L-NAME did not affect superoxide levels under reoxygenated conditions in HPAECs, suggesting that uncoupled eNOS did not contribute to increased ROS levels under reoxygenated conditions. Similarly, inhibitors of mitochondrial ROS generation were not as effective in lowering superoxide levels under these conditions. Instead, NADPH oxidases primarily contributed to superoxide induction under reoxygenation. Interestingly, the NADPH oxidase subunit, NOX4, which has been previously shown to be induced under hypoxia in vitro and in vivo (16, 43), was also elevated in hypoxic HPAECs and lung tissue from chronic hypoxic mice. This supports earlier observations that hypoxic induction of NOX4 promotes ROS generation upon reoxygenation (16). Similarly, ROS generation was also decreased in hypoxic lung tissues derived from NOX2 knockout mice $(24,41)$, further supporting the notion that NADPH oxidases importantly contribute to ROS generation upon reoxygenation.

In contrast to superoxide, NO levels remained reduced under hypoxia-reoxygenation conditions, supporting the view that increased superoxide levels might scavenge NO, thereby lowering $\mathrm{NO}$ levels. In addition, the $\mathrm{BH}_{4} / \mathrm{BH}_{2}$ ratio remained reduced under hypoxia-reoxygenation conditions. This might also relate to increased levels of superoxide under these conditions, which can oxidize $\mathrm{BH}_{4}$ to $\mathrm{BH}_{2}$, thus reducing NO generation and increasing superoxide production. In line, $\mathrm{FA}$ increased $\mathrm{BH}_{4}$ bioavailability and $\mathrm{NO}$ generation also under hypoxia-reoxygenation conditions, while, possibly as a consequence, superoxide levels were reduced.

Thus, FA appears to have an important function in restoring and maintaining the balance between NO and ROS and thus counteracting endothelial dysfunction and other adverse effects under these conditions. In support, our data show that supplementation with FA improved acetylcholinedependent vasorelaxation in murine pulmonary vessels.

Although the decreased $\mathrm{BH}_{4} / \mathrm{BH}_{2}$ ratio together with the reduction of superoxide generation by L-NAME pointed toward uncoupled eNOS under hypoxia, we did not find evidence that de novo synthesis of biopterins was altered under these conditions. In contrast, a recent report suggested increased de novo synthesis of biopterins based on elevated levels of GTPCH-1, resulting in an increased $\mathrm{BH}_{4} / \mathrm{BH}_{2}$ ratio in hypoxia (18). However, in support of our observation, this finding was not confirmed by others $(23,36)$.

Instead, we observed decreased levels of DHFR under hypoxia. DHFR has been described to recycle $\mathrm{BH}_{2}$ to $\mathrm{BH}_{4}$, 
thereby maintaining the $\mathrm{BH}_{4}$ pool required for adequate NOS function (11). FA, which has been previously shown to upregulate DHFR levels under normoxic conditions (25), also effectively increased hypoxic DHFR levels. Importantly, FA restored $\mathrm{BH}_{4}$ levels and enhanced $\mathrm{NO}$ and nitrite levels under normoxia and hypoxia, and this effect was dependent on DHFR, further supporting our notion that the FA-induced increase in $\mathrm{NO}$ and $\mathrm{BH}_{4}$ levels is promoted by improved $\mathrm{BH}_{2}$ to $\mathrm{BH}_{4}$ recycling. However, while beneficial effects of FA on $\mathrm{BH}_{4}$ availability and eNOS uncoupling have been reported (25), for review, see (46), other studies failed to link the beneficial effect of FA on endothelial dysfunction to the regeneration or stabilization of $\mathrm{BH}_{4}$ (44).

Our study, however, showed that FA reversed eNOS monomerization under hypoxia, indicating recoupling of eNOS. In support, FA reduced hypoxia-induced phosphorylation of eNOS at Thr495, which acts to inhibit eNOS activity. Studies using phosphomutants of eNOS suggested that Thr495-phosphorylated eNOS can uncouple eNOS (40), further indicating that hypoxia results in eNOS uncoupling and FA is able to recouple this enzyme.

In support of our study, increased Thr495 eNOS levels under hypoxia have been reported $(50,52)$, while FA has been shown to dephosphorylate eNOS at Thr495 in porcine aortic endothelial cells (65). Furthermore, FA increased phosphorylation of eNOS at Ser1177, which has been attributed to Akt-induced activation of this enzyme, under normoxic and hypoxic conditions. This finding has been supported by a recent study demonstrating that FA can activate the PI3 kinase/Akt pathway (65) and thus Ser1177 phosphorylation of eNOS, indicating that FA acts beneficially on NO availability via different mechanisms.

Although the role of Ser1177 phosphorylation of eNOS under hypoxia is controversial, showing increased (9), unchanged (3), or decreased $(47,50,52)$ phosphorylation of eNOS at Ser1177, our data indicate that hypoxia increases Ser1177 phosphorylation in HPAECs and lung tissues in vivo, while NO levels were clearly decreased. This apparent discrepancy can be explained by previous findings that in the absence of $\mathrm{BH}_{4}$, eNOS Ser1177 phosphorylation is associated with increased superoxide rather than with NO production due to uncoupling of eNOS (8).

Together with our previous findings that Akt can be activated under hypoxic conditions (4) and the findings in this study that $\mathrm{BH}_{4}$ and $\mathrm{NO}$ levels are decreased under hypoxia, we assume that phosphorylation of eNOS at Ser1177 under hypoxic conditions might be linked to superoxide rather than to $\mathrm{NO}$ generation. In the presence of $\mathrm{FA}, \mathrm{BH}_{4}$ bioavailability increases, thus allowing the Ser1177-phosphorylated enzyme to generate NO again also under hypoxic conditions.

Our study now shows that FA effectively protects against the development of PH under hypoxia, as indicated by decreased RVP, PVR, and RVH, by improving $\mathrm{BH}_{4}$ recycling capacity and recoupling of eNOS. This might thus possibly add an additional important indication for therapy to the portfolio of FA treatment options. Interestingly, it was recently reported that treatment with sepiapterin, a commercially available modified $\mathrm{BH}_{2}$, did not ameliorate PVR in mice in response to chronic hypoxia (18).

While in this study $\mathrm{BH}_{4}$ levels seemed to be increased under hypoxic conditions, further increasing biopterin levels through application of sepiapterin might possibly be less efficient. Moreover, since sepiapterin needs to be converted to $\mathrm{BH}_{4}$ by DHFR to be fully active, the decreased capacity to recycle $\mathrm{BH}_{2}$ to $\mathrm{BH}_{4}$ under hypoxic conditions might limit this therapeutic approach. However, in support of our observations, a recent study suggested that supplementation with tetrahydrobiopterin might also have beneficial effects on $\mathrm{PH}$ induced by chronic hypoxia (23), although the mechanisms underlying this effect have not been analyzed in this study.

Although FA has been shown to have beneficial effects in coronary artery disease and other cardiovascular disorders associated with hypoxia and reoxygenation $(45,57,59)$, several clinical trials indicated controversial outcomes with regard to cardiovascular disease risk and mortality $(14,59$, 71). While multiple reasons have been indicated for the negative results in some studies (58), increasing evidence suggests that FA might be more beneficial in primary prevention in subjects with low FA levels (29). A recent, large clinical trial indicated a substantially reduced risk for stroke in hypertensive patients taking FA $(30,69)$.

While the results of our study in an animal model suggest that FA might be able to prevent the development of $\mathrm{PH}$ in conditions of hypoxia, such as a high altitude sojourn, or in hypoxemic patients at risk to develop PH; clearly, clinical trials will be required to assess the potential of FA as a preventive or treatment option for PH associated with low oxygen availability.

Collectively, our findings indicate that disruption of the $\mathrm{BH}_{4}$ to $\mathrm{BH}_{2}$ balance due to reduction of DHFR levels under hypoxia decreases NO bioavailability due to uncoupling of eNOS, subsequently promoting RVH and PVR and the development of PH. Since supplementation with FA restored NO metabolism under hypoxia and protected against the development of PVR and RVH and lowered RVP, FA may provide an efficient and cost-effective therapeutic strategy to combat PH.

\section{Materials and Methods}

\section{Chemicals}

All chemicals were from Sigma-Aldrich unless stated differently.

\section{Cell culture}

HPAECs were purchased from Invitrogen and grown according to the manufacturer's instructions. Experiments were performed with cells cultured in endothelial basal medium supplemented with $2 \%$ fetal calf serum. Cells were exposed to hypoxia $\left(1 \%\right.$ oxygen and $\left.5 \% \mathrm{CO}_{2}\right)$ for $24 \mathrm{~h}$ in a Ruskinn workstation (IUL).

\section{Gene silencing}

For gene silencing, HPAECs were transfected with short interfering RNA (siRNA) targeting human DHFR, 5'CAGUAGAAGGUAAACAGAAdTdT-3' (sense), or with control siRNA, 5'-GACUACUGGUCGUUGAAGUdTdT-3' (Ambion), using Lipofectamine RNAiMAX (Invitrogen) according to the manufacturer's instructions. At $24 \mathrm{~h}$ after transfection, cells were placed in $2 \%$ fetal calf serumcontaining medium for $16 \mathrm{~h}$ before hypoxic stimulation. siRNA transfection efficiency was validated by real-time quantitative polymerase chain reaction (RT-qPCR) and was on average $70-80 \%$. 


\section{Animals}

All animal procedures were performed in accordance with the European directive $86 / 609 / \mathrm{EEC}$ and approved by the local legislation on protection of animals (Government of Upper Bavaria, Munich, Germany) or the Czech Central Commission for Animal Welfare. For the experiments, C57BL/6 male mice (8 weeks old, 20-25 g; Charles River) were used. Each group consisted of eight mice. For ex vivo analyses, lungs were dissected and macerated, and intact PAs were isolated. PAs were placed in MCDB131 medium and exposed to hypoxia for $24 \mathrm{~h}$. For in vivo analyses, mice were exposed to chronic normobaric hypoxia $\left(10 \% \mathrm{O}_{2}\right)$ in a ventilated chamber (Ing. Humbs, Valley, Germany) for 2 weeks. Age-matched control animals breathed room air. Normoxic and hypoxic groups received FA $(5 \mathrm{mg} / \mathrm{kg} /$ day) by dietary supplementation.

\section{Hemodynamic measurements}

Mice were anesthetized by isoflurane, weighed, and the left chest was shaved. RVP was determined hemodynamically in a transthoracic approach. Hemodynamic measurements were performed using a $24 \mathrm{G}$ needle connected to a pressure amplifier (Isotec) and recorded using HSE-HA HAEMODYN W software for hemodynamic studies. The catheter was inserted into the left ventricle (LV) and then carefully advanced to the RV. The correct position was confirmed by observing the characteristic ventricular waveforms. The pressure profile was recorded after stabilization for $1 \mathrm{~min}$, and systolic RVP values were determined. Mice were euthanized in anesthesia by cervical dislocation.

\section{Immunoblot analysis}

Proteins were isolated and Western blot analyses were performed as previously described (7) using antibodies against DHFR, eNOS (both from BD Transduction Laboratories), phospho-eNOS (Ser-1177 and Thr-495) (both Cell Signaling), NOX4 (Epitomics), and $\beta$-actin (Santa Cruz). Goat anti-mouse or rabbit anti-goat immunoglobulin G (Millipore) secondary antibodies were used. The enhanced chemiluminescence Western blotting system (GE Healthcare) was used for detection.

\section{Gene expression analysis}

Total RNA was isolated using the RNeasy Mini Kit (Qiagen) according to the manufacturer's protocol. cDNA was synthesized from isolated RNA using the high-capacity cDNA reverse transcription kit (Qiagen) according to the manufacturer's instructions in a 6000 Rotor Gene Real-Time PCR System (Qiagen). RT-qPCR was performed using gene-specific primers as follows: DHFR 5'-CAC AAA TCA GAC GGC AGC ACT-3' (sense), 5'-CAT CGG GCG TGG TGA ACT C-3' (antisense); 18S rRNA 5'-GTA ACC CGT TGA ACC CCA TT-3' (sense), 5'-CCA TCC AAT CGG TAG TAG CG-3' (antisense). The samples were loaded in triplicate for each primer pair, and the value of each sample was normalized to $18 \mathrm{~S}$ rRNA. All data were analyzed by the system software (Qiagen).

\section{eNOS dimerization assay}

Low-temperature sodium dodecyl sulfate-polyacrylamide gel electrophoresis (SDS-PAGE) was performed for detec- tion of eNOS dimers as described elsewhere $(35,72)$. Briefly, protein samples in Laemmli buffer without 2-mercaptoethanol were incubated at $37^{\circ} \mathrm{C}$ for $5 \mathrm{~min}$ and thereafter separated by $8 \%$ SDS-PAGE. Gels and buffers were equilibrated at $4^{\circ} \mathrm{C}$ before electrophoresis, and SDS-PAGE separation was performed on ice. Western blotting was performed using an eNOS antibody. Total eNOS levels were assessed by immunoblot.

\section{Measurement of superoxide anion production by EPR}

Cells or tissues were washed once in $1 \times$ phospho-buffer saline and harvested in Krebs-Hepes buffer $(\mathrm{NaCl} 99 \mathrm{mM}$, $\mathrm{KCl} 4.69 \mathrm{~m} M, \mathrm{NaHCO}_{3} 25 \mathrm{~m} M, \mathrm{KH}_{2} \mathrm{PO}_{4} 1.03 \mathrm{~m} M$, D-glucose $5.6 \mathrm{~m} M$, Na-HEPES $20 \mathrm{~m} M, \mathrm{CaCl}_{2} 2.5 \mathrm{~m} M, \mathrm{MgSO}_{4} 1.2 \mathrm{~m} M$ ). Samples were prepared in either hypoxic or normoxic conditions by adding $5 \mu M$ diethyldithiocarbamate (DETC), $25 \mu M$ desferroxamine (DES), and $100 \mu M$ superoxide-specific spin probe (1-hydroxy-methoxycarbonyl-2,2,5,5-tetramethylpyrrolidine hydrochloride $[\mathrm{CMH}]$ ) (Noxygen) (17). Cell suspensions or tissues were placed in airtight glass capillaries and spectra were recorded in an EPR spectrometer with temperature-controlled resonator Escan (Bruker). EPR settings for $\mathrm{CMH}$ spin label were center field $3455 \mathrm{G}$, sweep width $10 \mathrm{G}$, frequency $9.7690 \mathrm{GHz}$, microwave power $23.89 \mathrm{~mW}$, and modulation amplitude $2.93 \mathrm{G}$. Spectra were recorded over $10 \mathrm{~min}$.

\section{Detection of superoxide anion by HPLC}

DHE (Sigma-Aldrich) was used for superoxide detection at a final concentration of $50 \mu M$, as described previously (21). Samples were prepared in Krebs-Hepes buffer and incubated with $\mathrm{DHE}(10 \mu M)$ at $37^{\circ} \mathrm{C}$ for $1 \mathrm{~h}$, additionally washed twice with Krebs-Hepes buffer, homogenized, and 2hydroxy-ethidium was extracted in methanol; 2-hydroxyethidium was separated on a C18 column (Sulpelco C18 column $4.6 \times 250 \mathrm{~mm}, 5 \mu \mathrm{m}$ ) and detected by a fluorescence detector (excitation $480 \mathrm{~nm}$ and emission $580 \mathrm{~nm}$ ) in $0.5 \mathrm{ml} /$ $\mathrm{ml}$ flow of increased $10-70 \%$ gradient of $60 \%$ acetonitrile in methanol and $0.1 \%$ trifluoroacetic acid. Retention time of 2-hydroxy-ethidium was $37.5 \mathrm{~min}$.

\section{Detection of NO radical by EPR}

Freshly prepared iron $\left(2^{+}\right)$-diethyldithiocarbamic acid $\left[\mathrm{Fe}\left(2^{+}\right)\right.$DETC $]$colloid complex was used for NO detection at a final concentration of $2 \mathrm{~m} M$. Samples were prepared in Krebs-Hepes buffer in normoxic or hypoxic conditions. Cell suspensions or tissues were incubated with $\mathrm{Fe}\left(2^{+}\right)$DETC in a $1-\mathrm{ml}$ syringe, and then snap-frozen in liquid nitrogen and stored at $-80^{\circ} \mathrm{C}$. Spectra were recorded by EPR using a Dewar flask filled with liquid nitrogen. EPR settings were center field $3425 \mathrm{G}$, sweep width $100 \mathrm{G}$, frequency $9.7704 \mathrm{GHz}$, power $47.66 \mathrm{~mW}$, and modulation amplitude $10.38 \mathrm{G}$.

\section{Detection of nitrite levels by HPLC}

Nitrites were detected in the cell culture medium supernatant by the reaction with 2, 3-diaminonaphtalene (DAN; Sigma-Aldrich) in acetic conditions. One hundred microliters of the sample was incubated with $10 \mu \mathrm{l}$ of $0.05 \mathrm{mg} / \mathrm{ml}$ of DAN in $6 \mathrm{M} \mathrm{HCl}$ for $10 \mathrm{~min}$. Then, $30 \mu \mathrm{l}$ of $10 \mathrm{M} \mathrm{NaOH}$ was added to neutralize the mixture. Nitrates were reduced to 
nitrite by nitrate reductase for $1 \mathrm{~h}$ using $150 \mathrm{mU} / \mathrm{ml}$ of nitrate reductase and $0.5 \mathrm{~m} M$ of NADPH. Nitrated fluorescent DAN adduct was separated on a C18 column (Sulpelco C18 column $4.6 \times 250 \mathrm{~mm}, 5 \mu \mathrm{m})$ and detected by a fluorescence detector (excitation $365 \mathrm{~nm}$ and emission $415 \mathrm{~nm}$ ) in $1 \mathrm{ml} / \mathrm{ml}$ flow of $5 \mathrm{mM} \mathrm{NaH} \mathrm{PO}_{4}$ in $50 \%$ methanol. Retention time of $\mathrm{NO}_{2}-$ DAN was $9.2 \min (21)$.

\section{Tetrahydrobiopterin assay}

Cells or tissues were harvested, homogenized in $0.1 \mathrm{M}$ phosphoric acid, $1 \mathrm{~m} M$ ethylenediaminetetraacetic acid (EDTA), and $10 \mathrm{~m} M$ dithiothreitol (DDT), and incubated on ice in the dark for $20 \mathrm{~min}$. After spinning down at 12,000 $\mathrm{g}$ for $3 \mathrm{~min}$, the supernatant was divided for acidic and alkaline oxidation of $\mathrm{BH}_{4}$ and incubated either with $2.5 \% \mathrm{I}_{2}, 10 \% \mathrm{KI}, 0.2 \mathrm{M}$ trichloroacetic acid (TCA; acetic condition) or $5 \mathrm{M} \mathrm{NaOH}$ and $0.9 \% \mathrm{I}_{2}, 1.8 \%$ $\mathrm{KCl}, 0.1 M \mathrm{NaOH}$ (alkaline condition). After incubation for $10 \mathrm{~min}$ in the dark, $2 \%$ ascorbate and water (acetic condition) or $2 M$ TCA and $2 \%$ ascorbate (alkaline condition) were added. Samples were spun down at 30,000 $g$ for $10 \mathrm{~min}$ and acetic acid was added to stabilize biopterin and pterin. Biopterin and pterin were separated on a C18 column detected by the fluorescent detector (excitation $350 \mathrm{~nm}$ and emission $450 \mathrm{~nm}$ ) in $1.5 \mathrm{ml} / \mathrm{ml}$ flow of $5 \mathrm{mM} \mathrm{NaH} \mathrm{PO}_{4}$ in $5 \%$ methanol pH 3.5. Retention time of biopterin was $8.6 \mathrm{~min}$.

\section{[NO radical-hemoglobin] complex detection by EPR}

Blood collected from mice at death was fractionated to plasma and red blood cell (RBC) fractions. RBC fractions were snap-frozen in 1-ml syringes in liquid nitrogen and loaded for spectral detection by EPR. NO-hemoglobin ( $\mathrm{HbNO}$ ) was registered directly by its triple peak. EPR settings for $\mathrm{HbNO}$ were center field $3320 \mathrm{G}$, sweep width $320 \mathrm{G}$, microwave power $10 \mathrm{~mW}$ and modulation amplitude $3 \mathrm{G}$, time constant $5242 \mathrm{~ms}$, conversion time $655 \mathrm{~ms}$, and number of scans 15 .

\section{Gross morphology analysis}

For analysis of the gross morphologic features of the heart in situ, the thoracic wall was opened and RIV and the RDM, as well as the heart apex were visualized. Pictures were taken using an Olympus E520 (Olympus) camera mounted on a compact tripod positioned directly on the dissection table, with 14-42 Olympus ED zoom lens (Olympus), set at a focal length of $30 \mathrm{~mm}$. Subsequently, hearts were explanted and positioned on their right side to visualize alterations of the right chamber. Pictures were taken with the same camera and objective set at the focal length of $40 \mathrm{~mm}$. All images were obtained in high-definition JPG format at a resolution of 10 megapixels and processed in GIMP 2.6.11 software (www.gimp.org). Angles between the bars marking the RIV and the RDM were measured by a standard transparent manual protractor on A5 printouts of the images and taken as a macroscopic measure of RVH. The pictures of the explanted hearts were analyzed for visible protrusion of the right chamber in front of the interventricular sulcus.

\section{Immunohistochemistry and histological analyses}

Isolated lung tissue samples and hearts were immersed in $10 \%$ buffered formalin solution for $48 \mathrm{~h}$ and subsequently embedded in paraffin (FFPE). FFPE lung and heart sections were stained with an antibody against $\alpha$-SMA (clone 1A4; DAKO). In brief, slides were heated at $60^{\circ} \mathrm{C}$ for $1 \mathrm{~h}$ before rehydration in decrement alcohol concentration raw. The endogenous peroxidase activity was quenched in $1 \%$ hydrogen peroxide solution in methanol. The hydration process was completed by rinsing in DAKO wash buffer (DAKO). Sections were heated in a water bath at $90^{\circ} \mathrm{C}$ while submerged in antigen retrieval $\mathrm{pH} 9$ epitope retrieval solution (DAKO) for $30 \mathrm{~min}$. Sections were blocked in blocking reagent for $1 \mathrm{~h}$, and then incubated with the antibody $1: 100$ diluted in $\mathrm{M} * \mathrm{O} * \mathrm{M}$ diluent (Vector $\mathrm{M} * \mathrm{O} * \mathrm{M}$ kit) (Vector Laboratories) for $1 \mathrm{~h}$ at room temperature in a humidity chamber. Sections were washed in DAKO wash buffer and secondary antibody was applied (anti-mouse IgG in dilution 1:250). The avidin-biotin complex (Vectastatin Elite Kit, Vector Laboratories) was applied to the slides for $30 \mathrm{~min}$ at room temperature. The chromogenic reaction was performed with diaminobenzidine (DAB; DAKO) for $5 \mathrm{~min}$ at room temperature. Slides were counterstained with Mayer's hematoxylin for $30 \mathrm{~s}$ (Merck), dehydrated in ascending alcohol raw, and mounted with Entelan (Merck). Positive and negative controls were included with each run. Two experienced pathologists scored blindly each tissue section for $\alpha$-SMA expression based on a semiquantitative scoring system that measured intensity ( 0 , negative; 1 , borderline; 2 , weak; 3 , moderate; 4 , strong) and percentage of positive cells (1-100).

\section{Right ventricular hypertrophy}

Hearts were removed and dissected to isolate the free wall of the RV from the LV and septum (S). The ratio of RV weight to left ventricle plus septum $(\mathrm{LV}+\mathrm{S})$ weight $(\mathrm{RV} /$ $\mathrm{LV}+\mathrm{S}$ ) (Fulton Index) was used to estimate RVH. In addition, whole heart sections were dehydrated and stained in 3\% Giemsa solution (Merck). Pictures were taken on the Zeiss Axiophot microscope (Zeiss) equipped with a CCD camera. The measurement was done using the Zeiss Axio Vision measurement module. Three measurements of the RV wall were taken per section: one of the center wall thickness and two $1 \mathrm{~mm}$ above and $1 \mathrm{~mm}$ below the wall midline. All pictures were processed in GIMP 2.6.11 (www.gimp.org).

\section{Ex vivo assessment of vascular reactivity by wire myography}

Explanted PAs were cut into segments, mounted in a myograph chamber (Dual Wire Myograph System 410A, DMT A/S), and equilibrated for $30 \mathrm{~min}$ in oxygenated (5\% $\mathrm{CO}_{2}, 95 \% \mathrm{O}_{2}$ mixture) physiological salt solution (composition in $\mathrm{mM}: \mathrm{NaCl} 118.99, \mathrm{KCl} 4.69, \mathrm{NaHCO}_{3} 25, \mathrm{MgSO}_{4} .7-$ $\mathrm{H}_{2} \mathrm{O}$ 1.17, $\mathrm{KH}_{2} \mathrm{PO}_{4} 1.18, \mathrm{CaCl}_{2} .2 \mathrm{H}_{2} \mathrm{O} 2.5, \mathrm{Na}_{2}$ EDTA 0.03, glucose 5.5), $\mathrm{pH} 7.4$, at $37^{\circ} \mathrm{C}$ to achieve a pretension of PAs equivalent to an in vivo lumen diameter in the relaxed state under a transmural pressure of $100 \mathrm{~mm} \mathrm{Hg}$. Working parameters for the measurement were then set to $90 \%$ of this value. The change in wall tension (active wall tension) was calculated as measured force divided by the double segment length and expressed in $\mathrm{mN} / \mathrm{mm}$. Resting wall tension (which arises from the properties of the passive elements in the vascular wall) was also determined after the normalization procedure. Forty-five minutes after normalization, modified physiological salt buffer was changed to a buffer, in which $\mathrm{NaCl}$ was exchanged for an 
equimolar concentration of $\mathrm{KCl}$-in whole $125 \mathrm{~m} M$ for 2 min-followed by washout with modified physiological salt buffer (15 min). Preconstriction was made by serotonin (Ser, $1 \mu M)$. When the contraction of the artery reached a steady state, increasing concentrations of acetylcholine (ACh, 0.001$0.3 \mu M$ ) were added in an increment manner to perform endothelium-dependent concentration-response curves. The same experiment was done with 20 min of preincubation with FA $(50 \mu M)$ in the bath medium. Data are presented as relative relaxation compared with serotonin-induced preconstriction.

\section{Statistical analysis}

All experimental data have been received from independent experiments. The sample size (number of independent experiments) required to reach an experimental power $(1-\beta)$ $\geq 0.8$ at a $p$-value threshold of 0.05 was calculated by power analysis using the power.t.test function in $\mathrm{R} 2.15$ (The $\mathrm{R}$ foundation). Independent sample preparations from different cellular batches or animals adjusted to the required sample size were then used. Values are presented as mean \pm SD. Results were compared by ANOVA for repeated measurements, followed by Student-Newman-Keuls $t$-test. $p<0.05$ was considered statistically significant. Post hoc power analysis to determine $(1-\beta)$ was performed using Kane SP. Post.ClinCalc: http://clincalc.com/Stats/Power.aspx. Updated November 20, 2014.

\section{Acknowledgments}

The authors thank Dr. Andreas Petry for help with the artwork and manuscript editing. This work was supported by grants from German Research Association (DFG-GO709/4 5), German Centre for Cardiovascular Research (DZHK), EU Seventh Framework Program (METOXIA) to A.G., GACR-13-01710S, BIOCEV-CZ.1.05/1.1.00/02.0109 to K.C., and European Cooperation in Science and Technology (COST Action BM1203/EU-ROS) to D.K.

\section{Author Disclosure Statement}

No competing financial interests exist.

\section{References}

1. Altenhofer S, Radermacher KA, Kleikers PW, Wingler K, and Schmidt HH. Evolution of NADPH oxidase inhibitors: selectivity and mechanisms for target engagement. Antioxid Redox Signal 23: 406-427, 2015.

2. Arnet UA, McMillan A, Dinerman JL, Ballermann B, and Lowenstein CJ. Regulation of endothelial nitric-oxide synthase during hypoxia. J Biol Chem 271: 15069-15073, 1996.

3. Bauer PM, Bauer EM, Rogers NM, Yao M, FeijooCuaresma M, Pilewski JM, Champion HC, Zuckerbraun BS, Calzada MJ, and Isenberg JS. Activated CD47 promotes pulmonary arterial hypertension through targeting caveolin-1. Cardiovasc Res 93: 682-693, 2012.

4. Belaiba RS, Bonello S, Zahringer C, Schmidt S, Hess J, Kietzmann T, and Gorlach A. Hypoxia up-regulates hypoxia-inducible factor-1alpha transcription by involving phosphatidylinositol 3-kinase and nuclear factor kappaB in pulmonary artery smooth muscle cells. Mol Biol Cell 18: 4691-4697, 2007.
5. Bendall JK, Alp NJ, Warrick N, Cai S, Adlam D, Rockett K, Yokoyama M, Kawashima S, and Channon KM. Stoichiometric relationships between endothelial tetrahydrobiopterin, endothelial NO synthase (eNOS) activity, and eNOS coupling in vivo: insights from transgenic mice with endothelial-targeted GTP cyclohydrolase 1 and eNOS overexpression. Circ Res 97: 864-871, 2005.

6. Bommel HM, Reif A, Frohlich LG, Frey A, Hofmann H, Marecak DM, Groehn V, Kotsonis P, La M, Koster S, Meinecke M, Bernhardt M, Weeger M, Ghisla S, Prestwich GD, Pfleiderer W, and Schmidt HH. Anti-pterins as tools to characterize the function of tetrahydrobiopterin in NO synthase. J Biol Chem 273: 33142-33149, 1998.

7. Bonello S, Zahringer C, BelAiba RS, Djordjevic T, Hess J, Michiels C, Kietzmann T, and Gorlach A. Reactive oxygen species activate the HIF-1alpha promoter via a functional NFkappaB site. Arterioscler Thromb Vasc Biol 27: 755761, 2007.

8. Chen CA, Druhan LJ, Varadharaj S, Chen YR, and Zweier JL. Phosphorylation of endothelial nitric-oxide synthase regulates superoxide generation from the enzyme. $J$ Biol Chem 283: 27038-27047, 2008.

9. Chen JX and Meyrick B. Hypoxia increases Hsp90 binding to eNOS via PI3K-Akt in porcine coronary artery endothelium. Lab Invest 84: 182-190, 2004.

10. Coggins MP and Bloch KD. Nitric oxide in the pulmonary vasculature. Arterioscler Thromb Vasc Biol 27: 1877-1885, 2007.

11. Crabtree MJ and Channon KM. Synthesis and recycling of tetrahydrobiopterin in endothelial function and vascular disease. Nitric Oxide 25: 81-88, 2011.

12. Crabtree MJ, Smith CL, Lam G, Goligorsky MS, and Gross SS. Ratio of 5,6,7,8-tetrahydrobiopterin to 7,8dihydrobiopterin in endothelial cells determines glucoseelicited changes in NO vs. superoxide production by eNOS. Am J Physiol Heart Circ Physiol 294: H1530-H1540, 2008.

13. Crabtree MJ, Tatham AL, Al-Wakeel Y, Warrick N, Hale AB, Cai S, Channon KM, and Alp NJ. Quantitative regulation of intracellular endothelial nitric-oxide synthase (eNOS) coupling by both tetrahydrobiopterin-eNOS stoichiometry and biopterin redox status: insights from cells with tet-regulated GTP cyclohydrolase I expression. J Biol Chem 284: 1136-1144, 2009.

14. Cui R, Iso H, Date C, Kikuchi S, and Tamakoshi A. Dietary folate and vitamin b6 and B12 intake in relation to mortality from cardiovascular diseases: Japan collaborative cohort study. Stroke 41: 1285-1289, 2010.

15. De Pascali F, Hemann C, Samons K, Chen CA, and Zweier JL. Hypoxia and reoxygenation induce endothelial nitric oxide synthase uncoupling in endothelial cells through tetrahydrobiopterin depletion and S-glutathionylation. Biochemistry 53: 3679-3688, 2014.

16. Diebold I, Petry A, Hess J, and Gorlach A. The NADPH oxidase subunit NOX4 is a new target gene of the hypoxia-inducible factor-1. Mol Biol Cell 21: 2087-2096, 2010.

17. Dikalov SI, Kirilyuk IA, Voinov M, and Grigor'ev IA. EPR detection of cellular and mitochondrial superoxide using cyclic hydroxylamines. Free Radic Res 45: 417430, 2011.

18. Dubois M, Delannoy E, Duluc L, Closs E, Li H, Toussaint C, Gadeau AP, Godecke A, Freund-Michel V, Courtois A, Marthan R, Savineau JP, and Muller B. Biopterin metabolism 
and eNOS expression during hypoxic pulmonary hypertension in mice. PLoS One 8: e82594, 2013.

19. Fagan KA, Fouty BW, Tyler RC, Morris KG, Jr., Hepler LK, Sato K, LeCras TD, Abman SH, Weinberger HD, Huang PL, McMurtry IF, and Rodman DM. The pulmonary circulation of homozygous or heterozygous eNOS-null mice is hyperresponsive to mild hypoxia. J Clin Invest 103: 291-299, 1999.

20. Fago A, Jensen FB, Tota B, Feelisch M, Olson KR, Helbo S, Lefevre S, Mancardi D, Palumbo A, Sandvik GK, and Skovgaard N. Integrating nitric oxide, nitrite and hydrogen sulfide signaling in the physiological adaptations to hypoxia: a comparative approach. Comp Biochem Physiol A Mol Integr Physiol 162: 1-6, 2012.

21. Fernandes DC, Wosniak J, Jr., Pescatore LA, Bertoline MA, Liberman M, Laurindo FR, and Santos CX. Analysis of DHE-derived oxidation products by HPLC in the assessment of superoxide production and NADPH oxidase activity in vascular systems. Am J Physiol Cell Physiol 292: C413-C422, 2007.

22. Fike CD, Pfister SL, Slaughter JC, Kaplowitz MR, Zhang Y, Zeng H, Frye NR, and Aschner JL. Protein complex formation with heat shock protein 90 in chronic hypoxia-induced pulmonary hypertension in newborn piglets. Am J Physiol Heart Circ Physiol 299: H1190H1204, 2010.

23. Francis BN, Hale A, Channon KM, Wilkins MR, and Zhao L. Effects of tetrahydrobiopterin oral treatment in hypoxiainduced pulmonary hypertension in rat. Pulm Circ 4: 462470, 2014.

24. Fresquet F, Pourageaud F, Leblais V, Brandes RP, Savineau JP, Marthan R, and Muller B. Role of reactive oxygen species and gp91phox in endothelial dysfunction of pulmonary arteries induced by chronic hypoxia. $\mathrm{Br} J$ Pharmacol 148: 714-723, 2006.

25. Gao L, Chalupsky K, Stefani E, and Cai H. Mechanistic insights into folic acid-dependent vascular protection: dihydrofolate reductase (DHFR)-mediated reduction in oxidant stress in endothelial cells and angiotensin II-infused mice: a novel HPLC-based fluorescent assay for DHFR activity. J Mol Cell Cardiol 47: 752-760, 2009.

26. Gielis JF, Lin JY, Wingler K, Van Schil PE, Schmidt HH, and Moens AL. Pathogenetic role of eNOS uncoupling in cardiopulmonary disorders. Free Radic Biol Med 50: 765776, 2011.

27. Gorlach A and Kietzmann T. Superoxide and derived reactive oxygen species in the regulation of hypoxiainducible factors. Methods Enzymol 435: 421-446, 2007.

28. Ho JJ, Man HS, and Marsden PA. Nitric oxide signaling in hypoxia. J Mol Med (Berl) 90: 217-231, 2012.

29. Holmes MV, Newcombe P, Hubacek JA, Sofat R, Ricketts SL, Cooper J, Breteler MM, Bautista LE, Sharma P, Whittaker JC, Smeeth L, Fowkes FG, Algra A, Shmeleva V, Szolnoki Z, Roest M, Linnebank M, Zacho J, Nalls MA, Singleton AB, Ferrucci L, Hardy J, Worrall BB, Rich SS, Matarin M, Norman PE, Flicker L, Almeida OP, van Bockxmeer FM, Shimokata H, Khaw KT, Wareham NJ, Bobak M, Sterne JA, Smith GD, Talmud PJ, van Duijn C, Humphries SE, Price JF, Ebrahim S, Lawlor DA, Hankey GJ, Meschia JF, Sandhu MS, Hingorani AD, and Casas JP. Effect modification by population dietary folate on the association between MTHFR genotype, homocysteine, and stroke risk: a meta-analysis of genetic studies and randomised trials. Lancet 378: 584-594, 2011.
30. Huo Y, Li J, Qin X, Huang Y, Wang X, Gottesman RF, Tang G, Wang B, Chen D, He M, Fu J, Cai Y, Shi X, Zhang Y, Cui Y, Sun N, Li X, Cheng X, Wang J, Yang X, Yang T, Xiao C, Zhao G, Dong Q, Zhu D, Ge J, Zhao L, Hu D, Liu L, and Hou FF. Efficacy of folic acid therapy in primary prevention of stroke among adults with hypertension in China: the CSPPT randomized clinical trial. JAMA 313: 1325-1335, 2015.

31. Jin RC and Loscalzo J. Vascular nitric oxide: formation and function. J Blood Med 2010: 147-162, 2010.

32. Justice JM, Tanner MA, and Myers PR. Endothelial cell regulation of nitric oxide production during hypoxia in coronary microvessels and epicardial arteries. J Cell Physiol 182: 359-365, 2000.

33. Karbach S, Wenzel P, Waisman A, Munzel T, and Daiber A. eNOS uncoupling in cardiovascular diseases - the role of oxidative stress and inflammation. Curr Pharm Des 20: 3579-3594, 2014.

34. Khoo JP, Zhao L, Alp NJ, Bendall JK, Nicoli T, Rockett K, Wilkins MR, and Channon KM. Pivotal role for endothelial tetrahydrobiopterin in pulmonary hypertension. Circulation 111: 2126-2133, 2005.

35. Klatt P, Schmidt K, Lehner D, Glatter O, Bachinger HP, and Mayer B. Structural analysis of porcine brain nitric oxide synthase reveals a role for tetrahydrobiopterin and Larginine in the formation of an SDS-resistant dimer. EMBO J 14: 3687-3695, 1995.

36. Koubsky K, Durisova J, Mikova D, and Herget J. Chronic hypoxia inhibits tetrahydrobiopterin-induced NO production in rat lungs. Respir Physiol Neurobiol 185: 547-552, 2013.

37. Laufs U, Fata VL, and Liao JK. Inhibition of 3-hydroxy-3methylglutaryl (HMG)-CoA reductase blocks hypoxia-mediated down-regulation of endothelial nitric oxide synthase. J Biol Chem 272: 31725-31729, 1997.

38. Le Cras TD and McMurtry IF. Nitric oxide production in the hypoxic lung. Am J Physiol Lung Cell Mol Physiol 280: L575-L582, 2001.

39. Liao JK, Zulueta JJ, Yu FS, Peng HB, Cote CG, and Hassoun PM. Regulation of bovine endothelial constitutive nitric oxide synthase by oxygen. J Clin Invest 96: 26612666, 1995.

40. Lin MI, Fulton D, Babbitt R, Fleming I, Busse R, Pritchard KA, Jr., and Sessa WC. Phosphorylation of threonine 497 in endothelial nitric-oxide synthase coordinates the coupling of L-arginine metabolism to efficient nitric oxide production. J Biol Chem 278: 44719-44726, 2003.

41. Liu JQ, Zelko IN, Erbynn EM, Sham JS, and Folz RJ. Hypoxic pulmonary hypertension: role of superoxide and NADPH oxidase (gp91phox). Am J Physiol Lung Cell Mol Physiol 290: L2-L10, 2006.

42. Matsui H, Shimosawa T, Itakura K, Guanqun X, Ando K, and Fujita T. Adrenomedullin can protect against pulmonary vascular remodeling induced by hypoxia. Circulation 109: 2246-2251, 2004.

43. Mittal M, Roth M, Konig P, Hofmann S, Dony E, Goyal P, Selbitz AC, Schermuly RT, Ghofrani HA, Kwapiszewska G, Kummer W, Klepetko W, Hoda MA, Fink L, Hanze J, Seeger W, Grimminger F, Schmidt HH, and Weissmann N. Hypoxia-dependent regulation of nonphagocytic NADPH oxidase subunit NOX4 in the pulmonary vasculature. Circ Res 101: 258-267, 2007.

44. Moat SJ, Clarke ZL, Madhavan AK, Lewis MJ, and Lang D. Folic acid reverses endothelial dysfunction induced by 
inhibition of tetrahydrobiopterin biosynthesis. Eur J Pharmacol 530: 250-258, 2006.

45. Moens AL, Claeys MJ, Wuyts FL, Goovaerts I, Van Hertbruggen E, Wendelen LC, Van Hoof VO, and Vrints CJ. Effect of folic acid on endothelial function following acute myocardial infarction. Am J Cardiol 99: 476-481, 2007.

46. Moens AL, Vrints CJ, Claeys MJ, Timmermans JP, Champion HC, and Kass DA. Mechanisms and potential therapeutic targets for folic acid in cardiovascular disease. Am J Physiol Heart Circ Physiol 294: H1971-H1977, 2008.

47. Murata T, Sato K, Hori M, Ozaki H, and Karaki H. Decreased endothelial nitric-oxide synthase (eNOS) activity resulting from abnormal interaction between eNOS and its regulatory proteins in hypoxia-induced pulmonary hypertension. J Biol Chem 277: 44085-44092, 2002.

48. Nandi M, Miller A, Stidwill R, Jacques TS, Lam AA, Haworth S, Heales S, and Vallance P. Pulmonary hypertension in a GTP-cyclohydrolase 1-deficient mouse. Circulation 111: 2086-2090, 2005.

49. Nichol CA, Smith GK, and Duch DS. Biosynthesis and metabolism of tetrahydrobiopterin and molybdopterin. Annu Rev Biochem 54: 729-764, 1985.

50. Ostergaard L, Stankevicius E, Andersen MR, EskildsenHelmond Y, Ledet T, Mulvany MJ, and Simonsen U. Diminished NO release in chronic hypoxic human endothelial cells. Am J Physiol Heart Circ Physiol 293: H2894-H2903, 2007.

51. Ozaki M, Kawashima S, Yamashita T, Ohashi Y, Rikitake Y, Inoue N, Hirata KI, Hayashi Y, Itoh H, and Yokoyama M. Reduced hypoxic pulmonary vascular remodeling by nitric oxide from the endothelium. Hypertension 37: 322327, 2001.

52. Prieto CP, Krause BJ, Quezada C, San Martin R, Sobrevia L, and Casanello P. Hypoxia-reduced nitric oxide synthase activity is partially explained by higher arginase-2 activity and cellular redistribution in human umbilical vein endothelium. Placenta 32: 932-940, 2011.

53. Pritchard KA, Jr., Shi Y, and Konduri GG. Tetrahydrobiopterin in pulmonary hypertension: pulmonary hypertension in guanosine triphosphate-cyclohydrolase-deficient mice. Circulation 111: 2022-2024, 2005.

54. Rengasamy A and Johns RA. Determination of $\mathrm{Km}$ for oxygen of nitric oxide synthase isoforms. J Pharmacol Exp Ther 276: 30-33, 1996.

55. Semenza GL. New insights into nNOS regulation of vascular homeostasis. J Clin Invest 115: 2976-2978, 2005.

56. Shaul PW, North AJ, Brannon TS, Ujiie K, Wells LB, Nisen PA, Lowenstein CJ, Snyder SH, and Star RA. Prolonged in vivo hypoxia enhances nitric oxide synthase type I and type III gene expression in adult rat lung. Am J Respir Cell Mol Biol 13: 167-174, 1995.

57. Shirodaria C, Antoniades C, Lee J, Jackson CE, Robson MD, Francis JM, Moat SJ, Ratnatunga C, Pillai R, Refsum $\mathrm{H}$, Neubauer S, and Channon KM. Global improvement of vascular function and redox state with low-dose folic acid: implications for folate therapy in patients with coronary artery disease. Circulation 115: 2262-2270, 2007.

58. Stampfer M and Willett W. Folate supplements for stroke prevention: targeted trial trumps the rest. JAMA 313: 13211322, 2015.

59. Stanger O. Physiology of folic acid in health and disease. Curr Drug Metab 3: 211-223, 2002.

60. Storme L, Rairigh RL, Parker TA, Kinsella JP, and Abman $\mathrm{SH}$. Acute intrauterine pulmonary hypertension impairs endothelium-dependent vasodilation in the ovine fetus. Pediatr Res 45: 575-581, 1999.

61. Strijdom H, Friedrich SO, Hattingh S, Chamane N, and Lochner A. Hypoxia-induced regulation of nitric oxide synthase in cardiac endothelial cells and myocytes and the role of the PI3-K/PKB pathway. Mol Cell Biochem 321: 23-35, 2009.

62. Stroes E, Hijmering M, van Zandvoort M, Wever R, Rabelink TJ, and van Faassen EE. Origin of superoxide production by endothelial nitric oxide synthase. FEBS Lett 438: 161-164, 1998.

63. Su Y and Block ER. Role of calpain in hypoxic inhibition of nitric oxide synthase activity in pulmonary endothelial cells. Am J Physiol Lung Cell Mol Physiol 278: L1204L1212, 2000.

64. Takemoto M, Sun J, Hiroki J, Shimokawa H, and Liao JK. Rho-kinase mediates hypoxia-induced downregulation of endothelial nitric oxide synthase. Circulation 106: 57-62, 2002.

65. Taylor SY, Dixon HM, Yoganayagam S, Price N, and Lang D. Folic acid modulates eNOS activity via effects on posttranslational modifications and protein-protein interactions. Eur J Pharmacol 714: 193-201, 2013.

66. Thum T, Fraccarollo D, Schultheiss M, Froese S, Galuppo P, Widder JD, Tsikas D, Ertl G, and Bauersachs J. Endothelial nitric oxide synthase uncoupling impairs endothelial progenitor cell mobilization and function in diabetes. Diabetes 56: 666-674, 2007.

67. Umbrello M, Dyson A, Feelisch M, and Singer M. The key role of nitric oxide in hypoxia: hypoxic vasodilation and energy supply-demand matching. Antioxid Redox Signal 19: 1690-1710, 2013.

68. Venema RC, Ju H, Zou R, Ryan JW, and Venema VJ. Subunit interactions of endothelial nitric-oxide synthase. Comparisons to the neuronal and inducible nitric-oxide synthase isoforms. J Biol Chem 272: 1276-1282, 1997.

69. Wang X, Qin X, Demirtas H, Li J, Mao G, Huo Y, Sun N, Liu $\mathrm{L}$, and Xu X. Efficacy of folic acid supplementation in stroke prevention: a meta-analysis. Lancet 369: 1876-1882, 2007.

70. Xu XP, Liu Y, Tanner MA, Sturek M, and Myers PR. Differences in nitric oxide production in porcine resistance arteries and epicardial conduit coronary arteries. $J$ Cell Physiol 168: 539-548, 1996.

71. Yang HT, Lee M, Hong KS, Ovbiagele B, and Saver JL. Efficacy of folic acid supplementation in cardiovascular disease prevention: an updated meta-analysis of randomized controlled trials. Eur J Intern Med 23: 745-754, 2012.

72. Yang YM, Huang A, Kaley G, and Sun D. eNOS uncoupling and endothelial dysfunction in aged vessels. Am J Physiol Heart Circ Physiol 297: H1829-H1836, 2009.

73. Zuckerbraun BS, George P, and Gladwin MT. Nitrite in pulmonary arterial hypertension: therapeutic avenues in the setting of dysregulated arginine/nitric oxide synthase signalling. Cardiovasc Res 89: 542-552, 2011.

Address correspondence to: Prof. Agnes Görlach Experimental and Molecular Pediatric Cardiology German Heart Center Munich at the Technical University Munich Lazarettstr. 36 Munich 80636 Germany

E-mail: goerlach@dhm.mhn.de 
Date of first submission to ARS Central, March 12, 2015; date of final revised submission, September 21, 2015; date of acceptance, September 21, 2015.

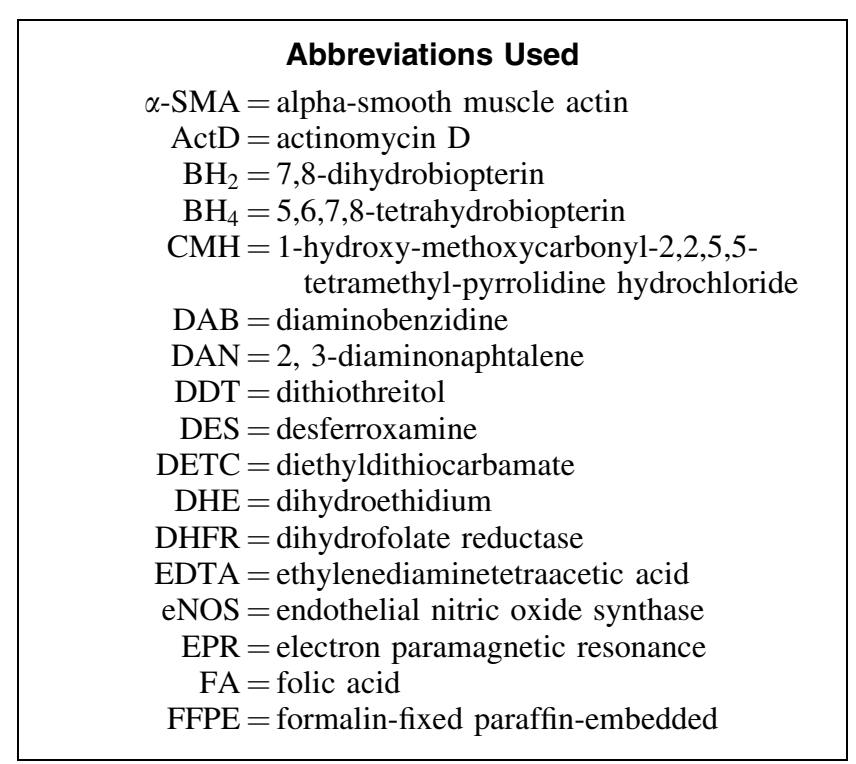

GTPCH-1 = GTP cyclohydrolase-1

HPLC $=$ high-pressure liquid chromatography

HPAEC $=$ human pulmonary artery endothelial cell

$\mathrm{L}-\mathrm{NAME}=\mathrm{L}-(\mathrm{G})$-nitro-L-arginine methyl ester

$\mathrm{LV}=$ left ventricle

$\mathrm{NO}=$ nitric oxide

NOS $=$ nitric oxide synthase

$\mathrm{O}_{2}{ }^{-}=$superoxide anion radical

PAs $=$ pulmonary arteries

$\mathrm{PCR}=$ polymerase chain reaction

$\mathrm{PH}=$ pulmonary hypertension

$\mathrm{PVR}=$ pulmonary vascular remodeling

$\mathrm{RDM}=$ right marginal coronary artery

$\mathrm{RBC}=$ red blood cell

$\mathrm{RIV}=$ left descending interventricular artery

$\mathrm{ROS}=$ reactive oxygen species

RT-qPCR $=$ real-time quantitative PCR

$\mathrm{RV}=$ right ventricle

$\mathrm{RVP}=$ right ventricular pressure

$\mathrm{RVH}=$ right ventricular hypertrophy

$\mathrm{S}=$ septum

SDS-PAGE = sodium dodecyl sulfate-polyacrylamide gel electrophoresis

$\mathrm{TCA}=$ trichloroacetic acid

TTFA $=2$-thenoyltrifluoroacetone 